\title{
Differential immunomodulation with long-chain $n-3$ PUFA in health and chronic disease
}

\author{
John W. C. Sijben ${ }^{1 *}$ and Philip C. Calder ${ }^{2}$ \\ ${ }^{1}$ Numico Research, Bosrandweg 20, 6704 PH Wageningen, The Netherlands \\ ${ }^{2}$ Institute of Human Nutrition, School of Medicine, University of Southampton, Bassett Crescent East, \\ Southampton SO16 7PX, UK
}

\begin{abstract}
The balance of intake of $n-6$ and $n-3$ PUFA, and consequently their relative incorporation into immune cells, is important in determining the development and severity of immune and inflammatory responses. Some disorders characterised by exaggerated inflammation and excessive formation of inflammatory markers have become among the most important causes of death and disability in man in modern societies. The recognition that long-chain $n-3$ PUFA have the potential to inhibit (excessive) inflammatory responses has led to a large number of clinical investigations with these fatty acids in inflammatory conditions as well as in healthy subjects. The present review explores the presence of dose-related effects of long-chain $n-3$ PUFA supplementation on immune markers and differences between healthy subjects and those with inflammatory conditions, because of the important implications for the transfer of information gained from studies with healthy subjects to patient populations, e.g. for establishing dose levels for specific applications. The effects of long-chain $n$-3 PUFA supplementation on ex vivo lymphocyte proliferation and cytokine production by lymphocytes and monocytes in healthy subjects have been studied in twenty-seven, twenty-five and forty-six treatment cohorts respectively, at intake levels ranging from $0.2 \mathrm{~g} \mathrm{EPA}+\mathrm{DHA} / \mathrm{d}$ to $7 \cdot 0 \mathrm{~g}$ $\mathrm{EPA}+\mathrm{DHA} / \mathrm{d}$. Most studies, particularly those with the highest quality study design, have found no effects on these immune markers. Significant effects on lymphocyte proliferation are decreased responses in seven of eight cohorts, particularly in older subjects. The direction of the significant changes in cytokine production by lymphocytes is inconsistent and only found at supplementation levels $\geq 2.0 \mathrm{~g}$ EPA + DHA/d. Significant changes in inflammatory cytokine production by monocytes are decreases in their production in all instances. Overall, these studies fail to reveal strong dose-response effects of EPA + DHA on the outcomes measured and suggest that healthy subjects are relatively insensitive to immunomodulation with longchain $n$-3 PUFA, even at intake levels that substantially raise their concentrations in phospholipids of immune cells. In patients with inflammatory conditions cytokine concentrations or production are influenced by EPA + DHA supplementation in a relatively large number of studies. Some of these studies suggest that local effects at the site of inflammation might be more pronounced than systemic effects and disease-related markers are more sensitive to the immunomodulatory effects, indicating that the presence of inflamed tissue or 'sensitised' immune cells in inflammatory disorders might increase sensitivity to the immunomodulatory effects of long-chain $n-3$ PUFA. In a substantial number of these studies clinical benefits related to the inflammatory state of the condition have been observed in the absence of significant effects on immune markers of inflammation. This finding suggests that conditionspecific clinical end points might be more sensitive markers of modulation by EPA + DHA than cytokines. In general, the direction of immunomodulation in healthy subjects (if any) and in inflammatory conditions is the same, which indicates that studies in healthy subjects are a useful tool to describe the general principles of immunomodulation by $n-3$ PUFA. However, the extent of the effect might be very different in inflammatory conditions, indicating that studies in healthy subjects are not particularly suitable for establishing dose levels for specific applications in inflammatory conditions. The reviewed studies provide no indications that the immunomodulatory effects of long-chain $n$-3 PUFA impair immune function or infectious
\end{abstract}

\footnotetext{
Abbreviations: ARA, arachidonic acid; Con A, concanavalin A; COPD, chronic obstructive pulmonary disease; IFN- $\gamma$, interferon- $\gamma$; LT, leukotrienes; LPS, lipopolysaccharide; NK, natural killer; PHA, phytohaemagglutinin; Th, T-helper.

*Corresponding author: Dr John W. C. Sijben, fax +31317 466500, email john.sijben@ @umico-research.nl
} 
disease resistance. In contrast, in some conditions the immunomodulatory effects of $\mathrm{EPA}+\mathrm{DHA}$ might improve immune function.

Immunomodulation: DHA: EPA: Health and chronic disease

PUFA have an important role in shaping and regulating inflammatory processes and responses (Calder, 2006). The balance of $n-6$ and $n-3$ PUFA might be important in determining the development and severity of inflammatory responses (Calder, 2006). Thus, a high intake of $n-6$ PUFA, particularly arachidonic acid (ARA; 20:4n-6), could potentiate inflammatory processes and so could predispose to or exacerbate inflammatory diseases. Alterations in the food chain and increased consumption of vegetable oils over the past century have led to alterations in $n-6$ and $n-3$ PUFA intakes, in favour of n-6 PUFA (Simopoulos, 1998). This development is likely to have increased the proportion of ARA in inflammatory cell phospholipids, as cell and tissue levels partly reflect dietary intake. Unfortunately, however, historical data to confirm this outcome are not available. On the other hand, increased consumption of $n-3$ PUFA, particularly the long-chain $n-3$ PUFA EPA (20:5n$3)$ and DHA (22:6n-3), increases the proportions of these fatty acids in inflammatory cell phospholipids (Calder, 2001a). The recognition that EPA and DHA have antiinflammatory properties (Calder, 2006) suggests that increasing their intake corrects the $n-6$ and $n-3$ PUFA balance, and so may act to decrease the risk of inflammatory conditions and be of benefit to patients with inflammatory diseases.

Some of the most important causes of death and disability in man are characterised by exaggerated inflammation and excessive formation of inflammatory eicosanoids and cytokines. These conditions and diseases include chronic obstructive pulmonary disease (COPD), rheumatoid arthritis, osteoarthritis, cachexia and inflammatory bowel diseases. In addition, many other diseases and conditions that are important causes of death and disability in developed regions have an inflammatory component that may be less pronounced. The latter include CVD, cerebrovascular disease, unipolar major depression, neurodegenerative disease, Alzheimer's disease, allergy, asthma, type 1 and type 2 diabetes and obesity. The onset of some of these disorders has been associated with low consumption of fish (which contain long-chain n-3 PUFA) and long-chain n-3 PUFA; in particular CVD (Daviglus et al. 1997; Oomen et al. 2000; Hallgren et al. 2001), depression (Hibbeln, 1998, 2002) and Alzheimer's disease (Morris et al. 2003). The role of excess inflammation in neural disorders is poorly understood. The essentiality of long-chain $n$-3 PUFA, particularly DHA as a structural component, for normal neural function may explain much of their importance. Some disorders with a more-pronounced and clearly-defined inflammatory character such as COPD (Murray \& Lopez, 1997), asthma (Bach, 2002) and Crohn's disease (Bach, 2002) have become more prevalent in most Western societies in the past decades, in parallel with greatly increased intake of $n-6$ PUFA. Clear associations between the risk of their onset and a shifted balance of $n$-6 PUFA and $n-3$ PUFA intake are lacking, but many investigators have recognised the potential of long-chain $n-3$ PUFA in dampening excessive inflammation in most of the inflammatory diseases and conditions listed earlier (Calder, 2006).

A large number of clinical investigations with longchain $n$-3 PUFA in chronic inflammatory disorders are now available, particularly in patients with rheumatoid arthritis, inflammatory bowel diseases and asthma (Calder, 2006). Generally, these studies have focused on disease-specific clinical outcomes rather than on markers of immunomodulation. In contrast, a large number of investigations with long-chain $n$-3 PUFA focusing on markers of immunomodulation have been performed with healthy subjects (Calder, 2001a). However, a common feature of intervention studies involving healthy subjects and some studies of subjects with inflammatory disorders is the measurement of similar immune markers. It is possible that the sensitivity of the immune system to interventions such as $n-3$ PUFA may be different in subjects with an inflammatory condition as compared with healthy subjects for whom the immune system may be buffered to a larger extent against modulation by such intervention. A difference in sensitivity would have important implications for the transfer of information gained from studies of healthy subjects to patient populations with inflammatory conditions, e.g. for establishing dose levels for specific applications. Thus, the current report reviews the immunomodulatory effects of long-chain $n-3$ PUFA in healthy human subjects as well as in patients with chronic disorders. The aim of the present review is to explore the presence of dose-related effects and differences between populations with different immune states. In order to make this comparison the present review will focus on the measurements that have been reported in studies involving healthy subjects as well as those reported in some studies of subjects with inflammatory disorders; i.e. lymphocyte proliferation, natural killer (NK) cell activity and production of cytokines by monocytes and lymphocytes.

\section{Dietary fatty acids, the inflammatory response and T-cell-mediated immunity}

The key link between fatty acids, inflammation and immunity is that eicosanoids, which are among the most important mediators and regulators of inflammation and immune responses, are generated from $\mathrm{C}_{20}$ PUFA. Since inflammatory cells typically contain a high proportion of the $n-6$ PUFA ARA and low proportions of other $\mathrm{C}_{20}$ PUFA (Calder, 2001a), ARA is usually the major substrate for eicosanoid synthesis. Eicosanoids, which include PG, thromboxanes, leukotrienes (LT) and other oxidised 
derivatives, are generated from ARA by the action of cyclooxygenase and lipoxygenase enzymes. These mediators are involved in modulating the intensity and duration of inflammatory responses (for reviews, see Lewis et al. 1990; Tilley et al. 2001), have cell- and stimulus-specific sources and frequently have opposing effects (Calder, 2006). Thus, the overall physiological (or pathophysiological) outcome will depend on the cells present, the nature of the stimulus, the timing of eicosanoid generation, the concentrations of different eicosanoids generated and the sensitivity of target cells and tissues to the eicosanoids generated. In general, pro-inflammatory roles have been ascribed to $\mathrm{PGE}_{2}$ and 4-series LT derived from ARA. For example, $\mathrm{PGE}_{2}$ induces fever, pain, vasodilation and vascular permeability, while $\mathrm{LTB}_{4}$ is chemotactic for leucocytes and induces the release of reactive oxygen species by neutrophils and inflammatory cytokines (TNF $\alpha$, IL-1 $\beta$, IL-6) by macrophages (Lewis et al. 1990; Tilley et al. 2001). In relation to cell-mediated immunity, $\mathrm{PGE}_{2}$ inhibits T-cell proliferation, the production of T-helper (Th)-1 type cytokines (IL-2 and interferon- $\gamma$ (IFN- $\gamma$ )) by $\mathrm{T}$-cells and promotes IgE production by B-cells. In contrast, $\mathrm{LTB}_{4}$ promotes the production of IL- 2 and IFN- $\gamma$ by T-cells, and enhances NK cell activity.

Animal feeding studies have shown a strong positive relationship between the amount of ARA in inflammatory cells and the ability of those cells to produce eicosanoids such as $\mathrm{PGE}_{2}$ (Peterson et al. 1998). In turn, the amount of ARA in inflammatory cells can be increased by including ARA in the diet of rats (Peterson et al. 1998) or by increasing the amount of ARA in the diet of human subjects (Thies et al. 2001c). The amount of ARA in inflammatory cells may also be influenced by the dietary intake of its precursor linoleic acid (18:2n-6), although the range of linoleic acid intake over which this relationship occurs has not been defined for man. The role of ARA as a precursor for the synthesis of eicosanoids indicates the potential for dietary $n$-6 PUFA (linoleic acid or ARA) to influence inflammatory and immune processes. The influence of increased dietary ARA has been investigated in two studies in healthy human subjects. In one study (Kelley et al. 1998a) healthy young males supplemented their diets with $1.5 \mathrm{~g} \mathrm{ARA} / \mathrm{d}$ for 7 weeks. This treatment was found to result in a marked increase in the production of $\mathrm{PGE}_{2}$ and $\mathrm{LTB}_{4}$ by bacterial lipopolysaccharide (LPS)stimulated mononuclear cells. However, production of TNF $\alpha$, IL- $1 \beta$ and IL- 6 by the latter was not found to be significantly altered (Kelley et al. 1998a). Similarly, ARA was found to have no effect on mitogen-stimulated T-cell proliferation (Kelley et al. 1997), NK cell activity (Kelley et al. 1997) or IL-2 production by mitogen-stimulated T-cells (Kelley et al. 1998a). Thus, increased ARA intake may result in changes indicative of selectively increased inflammation or inflammatory responses in man. In another study (Thies et al. 2001a,b,c) elderly subjects supplemented their diets with $0.7 \mathrm{~g}$ ARA/d for 12 weeks. This treatment was found to have no effect on LPS-stimulated production of TNF $\alpha$, IL-1 $\beta$ or IL-6 by mononuclear cells (Thies et al. 2001a), mitogen-stimulated T-cell proliferation (Thies et al. 2001c), production of IL-2 and IFN- $\gamma$ by $\mathrm{T}$-cells in response to mitogen (Thies et al. 2001c) or NK cell activity (Thies et al. 2001b). Taken together these studies suggest that moderately-increased intake of ARA by healthy subjects results in the incorporation of ARA into cells involved in inflammatory responses (Thies et al. 2001c) but does not affect the production of inflammatory cytokines, T-cell responses or NK cell activity (Thies $e t$ al. $2001 a, b, c)$, although the production of inflammatory eicosanoids is increased (Kelley et al. 1998a).

Increased consumption of the long-chain $n$-3 PUFA EPA and DHA results in increased proportions of these fatty acids in inflammatory cell phospholipids (Lee et al. 1985; Endres et al. 1989; Gibney \& Hunter, 1993; Sperling et al. 1993; Caughey et al. 1996; Healy et al. 2000; Yaqoob et al. 2000). The incorporation of EPA and DHA into human inflammatory cells occurs in a dose-response fashion (Healy et al. 2000) and is partly at the expense of ARA. Since there is less substrate available for synthesis of eicosanoids from ARA, fish oil supplementation of the human diet has been shown to result in decreased production of ARA-derived eicosanoids by inflammatory cells (for references, see Calder, 2006). Whereas these studies used fish oil providing both EPA and DHA, Kelley et al. (1999) have demonstrated that $6 \mathrm{~g}$ DHA/d results in decreased production of $\mathrm{PGE}_{2}$ (by $60 \%$ ) and $\mathrm{LTB}_{4}$ (by $75 \%$ ) by LPS-stimulated mononuclear cells.

EPA is also able to act as a substrate for both cyclooxygenase and lipoxygenase enzymes, giving rise to eicosanoids with a slightly different structure from those formed from ARA. Thus, fish oil supplementation of the human diet has been shown to result in increased production of 5-series LT and 5-hydroxyeicosapentaenoic acid by inflammatory cells (for references, see Calder, 2006). The functional importance of this difference is that the mediators formed from EPA are frequently less potent than those formed from ARA (Goldman et al. 1983; Lee et al. 1984; Bagga et al. 2003), although it is not always the case (Dooper et al. 2002; Miles et al. 2002, 2003). The reduction in generation of ARA-derived mediators that accompanies fish oil consumption has led to the notion that fish oil is anti-inflammatory and immunomodulatory.

In addition to long-chain $n$-3 PUFA modulating the generation of eicosanoids from ARA and to EPA acting as substrate for the generation of alternative eicosanoids, recent studies have identified a novel group of mediators, the E- and D-series resolvins formed from EPA and DHA respectively, that appear to exert anti-inflammatory and immunomodulatory actions (for reviews, see Serhan et al. 2004; Serhan, 2005).

Through the changed profiles of production of eicosanoids and other mediators, $n-3$ PUFA are expected to influence inflammatory processes and immune responses (Calder, 2003, 2006). Cell-culture and animal experiments have confirmed this expectation, although they have often involved high levels of exposure to the fatty acids under study and other experimental conditions that are not transferable to the human setting. Data from cell-culture and animal models reporting inflammatory and immune outcomes have been reviewed in detail elsewhere (Calder, 2001a, 2003, 2006; Calder et al. 2002) and will not be further discussed here. 


\section{Effects of long-chain $\boldsymbol{n}$-3 PUFA on immune markers in healthy subjects}

\section{Introductory comments}

There is a great deal of diversity in the measurements reported in the large number of studies investigating the effects of fish oil and other sources of EPA and DHA on markers of immune function in healthy subjects. The objective of the present review is to explore the extent to which long-chain $n-3$ PUFA influence immune outcomes in healthy subjects and how the effects in healthy subjects relate to those seen in patients with disorders characterised by the presence of (chronic) inflammation. Thus, the review is limited to immune markers reported in a substantial number of studies of healthy subjects as well as in studies of subjects with inflammatory disorders. The markers selected according to these criteria are ex vivo mitogen-induced $\mathrm{T}$ lymphocyte proliferation, NK cell activity, mitogen-induced cytokine production by lymphocytes and cytokine production by monocytes. Some of the best-quality markers of immunomodulation, e.g. delayedtype hypersensitivity response and vaccine-specific antibody response (Albers et al. 2005), are reported in too few studies to contribute to the objective of the present overview. Thus, the reviewed data do not provide a complete overview of all available data on the effects of dietary supplementation with EPA and DHA on immune function in healthy subjects.

Selected data are presented in Tables 1-3, in which studies are listed according to ascending EPA and DHA intake. This form of presentation was chosen to provide a clearer picture of potential dose-dependent effects. In addition, the percentage change associated with increased intake of $n-3$ PUFA reported in each study is depicted in Figs. 1-3 to help explore the presence of potential trends in results that were not shown to be significant, as studies could potentially lack the statistical power to find significance because of their small sample size and the large inter-individual variance in outcomes that is generally reported (see Albers et al. 2005). The current review covers studies with oral supplementation of fish oil capsules, purified EPA and/or DHA supplements, fish oil-enriched foods or diets with well-defined long-chain n-3 PUFA enrichment.

\section{Effects of EPA and DHA on ex vivo lymphocyte proliferation}

The effects of EPA and DHA on ex vivo lymphocyte proliferation in healthy subjects have been reported in fourteen publications at twenty-seven different dose levels ranging from 0.2 to $7 \mathrm{~g} \mathrm{EPA}+\mathrm{DHA} / \mathrm{d}$ (Table 1). Seven of these studies had a double-blind randomised placebocontrolled study design. Stimulants used to induce lymphocyte proliferation were concanavalin A (Con A) or phytohaemagglutinin (PHA), which are both mitogens for T-cells. In all cases, cells were from peripheral blood and they were frequently studied as a purified preparation of mononuclear cells, which comprise a mixture of lymphocytes and monocytes in an approximate ratio of $85: 15$.
Significantly increased lymphocyte proliferation $(P<$ $0.05)$ was found in only one cohort, at a dose level of $2.0 \mathrm{~g}$ EPA+DHA/d (Trebble et al. 2003b). In this open study, which investigated effects of increasing dose levels from baseline to $0 \cdot 3,1.0$ and $2.0 \mathrm{~g} / \mathrm{d}$, a trend towards a doseresponse relationship was found (Trebble et al. 2003b) that was accompanied by a dose-dependent decrease in $\mathrm{PGE}_{2}$ production and an increased IFN- $\gamma$ production at the highest intake level. Decreased lymphocyte proliferation was reported in seven treatment cohorts at dose levels of $0 \cdot 2-7 \cdot 0 \mathrm{~g} \mathrm{EPA}+\mathrm{DHA} / \mathrm{d}$. Five of these seven studies used an open trial design. In one of the two blinded studies the reported decrease in lymphocyte proliferation was only significantly different $(P<0.05)$ compared with baseline values but not compared with the placebo values (Bechoua et al. 2003). In nineteen treatment cohorts no significant effect on lymphocyte proliferation was reported; fourteen of these cohorts were in studies with a double blind placebo-controlled randomised design. In one of these studies the lymphocyte proliferation response to Con A was found to decrease significantly in all treatments $(P<0 \cdot 05)$, including the placebo, illustrating the importance of an adequate placebo control (Wallace et al. 2003). This finding emphasises that caution should be exercised in the interpretation of the results of open studies, since the studies with better-quality designs and similar dose levels generally do not confirm their findings.

Fig. 1 illustrates that those studies that reported significant $(P<0 \cdot 05)$ effects of $n-3$ PUFA were those that found the largest percentage changes in lymphocyte proliferation from baseline (i.e. before $n-3$ PUFA treatment). The cohorts with significantly decreased lymphocyte proliferation received doses of $n-3$ PUFA that seem randomly spread over the complete dose range studied, indicating the absence of a clear dose-response relationship.

Thus, while there is evidence in the literature to suggest that long-chain $n-3$ PUFA decrease the proliferative capacity of $\mathrm{T}$ lymphocytes, even more evidence suggests that there is no significant effect; there is relatively little evidence from healthy human volunteer studies to suggest that fish oil enhances $\mathrm{T}$ lymphocyte proliferation. The reasons for these different findings are not apparent. Many confounding factors have been suggested, such as gender, age, different vitamin E content of the capsules used and variations in cell-culture conditions (see Calder, 2001a). However, most of the factors that could potentially contribute to the variance between cohorts do not consistently influence the EPA and DHA effects in more than one study. For instance, Kramer and co-workers (Kramer et al. 1991) have found a significant decrease in lymphocyte proliferation following a high dose of fish oil, and this effect is completely reversed by concurrent supplementation of vitamin E. In contrast, Trebble et al. (2003b) have found no effect of co-administering an antioxidant mix with a fish oil supplement, and all other studies that have found decreased lymphocyte proliferation used capsules enriched with vitamin E (apart from one study that used fish; Meydani et al. 1993). On the other hand, the observation by Meydani et al. (1991) that older (female) subjects are more susceptible to the effects of long-chain $n-3$ PUFA is further supported by three other studies in elderly 
Table 1. Effects of EPA and DHA supplementation on ex vivo lymphocyte proliferation in healthy human subjects*

\begin{tabular}{|c|c|c|c|c|c|c|c|c|}
\hline \multirow[b]{2}{*}{ Reference } & \multirow[b]{2}{*}{ Type of study } & \multirow[b]{2}{*}{ Dose of EPA + DHA $(\mathrm{g} / \mathrm{d})$} & \multirow{2}{*}{$\begin{array}{l}\text { Duration } \\
\text { (weeks) }\end{array}$} & \multicolumn{3}{|c|}{ Subjects } & \multirow{2}{*}{$\begin{array}{l}\text { Stimulus } \\
\text { used }\end{array}$} & \multirow[b]{2}{*}{ Effect seent } \\
\hline & & & & $n$ & Gender & Age (years) & & \\
\hline Bechoua et al. (2003) & $\mathrm{DB}, \mathrm{PC}, \mathrm{R}$, parallel & $0.2(0.03+0.15)$ & 6 & 10 & $M+F$ & $70-83$, mean $75 \cdot 6$ & $\begin{array}{l}\text { Con A } \\
\text { PHA }\end{array}$ & $\begin{array}{l}\downarrow 45 \% \\
\downarrow 34 \%\end{array}$ \\
\hline Trebble et al. (2003b) & Open, parallel & $0.3(0.2+0.1)$ & 4 & 16 & M & mean 30 & Con A & None \\
\hline Wallace et al. (2003) & $\mathrm{DB}, \mathrm{PC}, \mathrm{R}$, parallel & $0.4(0.1+0.3)$ & 12 & 8 & M & $18-39$, mean 25 & Con A & None \\
\hline Thies et al. (2001c) & $\mathrm{DB}, \mathrm{PC}, \mathrm{R}$, parallel & $0.7 \mathrm{DHA}$ & 12 & 8 & $M+F$ & 58-71, mean 65 & Con A & None \\
\hline Kew et al. (2003) & $\mathrm{DB}, \mathrm{PC}, \mathrm{R}$, parallel & $0.77(0.3+0.47)$ & 24 & 30 & $M+F$ & 25-72, mean 52 & Con A & None \\
\hline Miles et al. (2004b) & $\mathrm{DB}, \mathrm{PC}, \mathrm{R}$, parallel & $\begin{array}{l}0.8(0.6+0.2)+0.6 \\
\text { GLA }+2.0 \text { ALA + } 0.7 \text { STA }\end{array}$ & 12 & $8-12$ & M & 21-44, mean 32 & Con A & None \\
\hline Wallace et al. (2003) & $\mathrm{DB}, \mathrm{PC}, \mathrm{R}$, parallel & $0.9(0.3+0.6)$ & 12 & 8 & M & 18-39, mean 25 & Con A & None \\
\hline Thies et al. (2001c) & $\mathrm{DB}, \mathrm{PC}, \mathrm{R}$, parallel & $1 \cdot 0(0 \cdot 7+0 \cdot 3)$ & 12 & 7 & $M+F$ & 60-68, mean 62 & Con A & $\downarrow 61 \%$ \\
\hline Trebble et al. (2003b) & Open, parallel & $1 \cdot 0(0 \cdot 7+0 \cdot 3)$ & 4 & 16 & M & mean 30 & Con A & None \\
\hline Miles et al. (2004b) & $\mathrm{DB}, \mathrm{PC}, \mathrm{R}$, parallel & $\begin{array}{l}1 \cdot 1(0.8+0.3)+0.8 \\
\text { GLA }+1 \cdot 3 \text { ALA + 0.4 STA }\end{array}$ & 12 & $8-12$ & M & 21-44, mean 32 & Con A & None \\
\hline Meydani et al. (1993) & Open, PC, parallel & $1 \cdot 23$ & 24 & 10 & $\mathrm{~F}$ & $>40$, mean 65 & $\begin{array}{l}\text { Con A } \\
\text { PHA }\end{array}$ & $\begin{array}{l}\downarrow 56 \% \\
\downarrow 53 \%\end{array}$ \\
\hline Molvig et al. (1991) & Open, PC & $1 \cdot 6(1 \cdot 0+0 \cdot 6)$ & 7 & 9 & M & mean 27 & PHA & $\downarrow 18 \%$ \\
\hline Miles et al. $(2004 b)$ & $\mathrm{DB}, \mathrm{PC}, \mathrm{R}$, parallel & $1.6(1 \cdot 1+0.5)+1 \cdot 0$ GLA & 12 & $8-12$ & M & 21-44, mean 32 & Con A & None \\
\hline Miles et al. (2006) & $\mathrm{DB}, \mathrm{PC}, \mathrm{R}$, parallel & $1.65(1.35+0.3)$ & 12 & 23 & M & 18-42, mean 24 & Con A & None \\
\hline Kew et al. (2003) & $\mathrm{DB}, \mathrm{PC}, \mathrm{R}$, parallel & $1 \cdot 7(0 \cdot 7+1 \cdot 0)$ & 24 & 30 & $M+F$ & 25-72, mean 54 & Con A & None \\
\hline Wallace et al. (2003) & $\mathrm{DB}, \mathrm{PC}, \mathrm{R}$, parallel & $1 \cdot 9(0 \cdot 5+1 \cdot 4)$ & 12 & 8 & M & 18-39, mean 22 & Con A & None \\
\hline Trebble et al. (2003b) & Open, parallel & $2 \cdot 0(1 \cdot 3+0 \cdot 7)$ & 4 & 16 & M & mean 30 & Con A & $\uparrow 92 \%$ \\
\hline Meydani et al. (1991) & Open, parallel & $2 \cdot 4(1 \cdot 7+0 \cdot 7)$ & 12 & 5 & $\mathrm{~F}$ & 23-33, mean 27 & $\begin{array}{l}\text { Con A } \\
\text { PHA }\end{array}$ & $\begin{array}{l}\text { None } \\
\text { None }\end{array}$ \\
\hline Meydani et al. (1991) & Open, parallel & $2 \cdot 4(1 \cdot 7+0 \cdot 7)$ & 12 & 6 & $\mathrm{~F}$ & 51-68, mean 61 & $\begin{array}{l}\text { Con A } \\
\text { PHA }\end{array}$ & $\begin{array}{l}\text { None } \\
\downarrow 36 \%\end{array}$ \\
\hline Miles et al. (2004b) & $\mathrm{DB}, \mathrm{PC}, \mathrm{R}$, parallel & $3.0(2 \cdot 1+0 \cdot 9)$ & 12 & 10 & M & 21-44, mean 32 & Con A & None \\
\hline Molvig et al. (1991) & Open, PC & $3 \cdot 2(2+1 \cdot 2)$ & 7 & 9 & M & mean 24 & PHA & $\downarrow 33 \%$ \\
\hline Miles et al. (2006) & DB, PC, R parallel & $3 \cdot 3(2 \cdot 7+0 \cdot 6)$ & 12 & 23 & M & 18-42, mean 25 & Con A & None \\
\hline Yaqoob et al. (2000) & $\mathrm{DB}, \mathrm{PC}, \mathrm{R}$, parallel & $3 \cdot 3(2 \cdot 1+1 \cdot 1)$ & 12 & 8 & $M+F$ & mean 39 & Con A & None \\
\hline Endres et al. (1993) & Open, non-parallel & $4 \cdot 7(2 \cdot 8+1 \cdot 9)$ & 6 & 9 & $\mathrm{M}$ & 21-39, mean 28 & PHA & None \\
\hline Miles et al. (2006) & DB, PC, R,parallel & $4.95(4.05+0.9)$ & 12 & 23 & M & 18-42, mean 24 & Con $\mathrm{A}$ & None \\
\hline Kelley et al. (1998b) & Open, PC, parallel & $6 \mathrm{DHA}$ & 13 & 7 & M & 20-40, mean 33 & $\begin{array}{l}\text { Con A } \\
\text { PHA }\end{array}$ & $\begin{array}{l}\text { None } \\
\text { None }\end{array}$ \\
\hline Kramer et al. (1991) & Open, parallel & $7(5+2)$ & 10 & 40 & M & 24-57, mean 38 & Con A & $\begin{array}{l}\downarrow 80 \% \text { (effect } \\
\text { reversed after } \\
\text { FO + vitamin E) }\end{array}$ \\
\hline
\end{tabular}

DB, double-blind; PC, placebo-controlled; R, randomised; ALA, $\alpha$-linolenic acid (18:3n-3); STA, stearidonic acid (18:4n-3); GLA, $\gamma$-linolenic acid (18:3n-6); Con A, concanavalin A; PHA, phytohaemagglutinin; $\downarrow$, reduction; FO, fish oil.

*The cohorts are listed according to ascending dose of EPA + DHA.

tThe effect is shown if it was significant $(P<0 \cdot 05)$. 
Table 2. Effects of EPA + DHA supplementation on ex vivo cytokine production by lymphocytes in healthy human subjects*

\begin{tabular}{|c|c|c|c|c|c|c|c|c|c|}
\hline \multirow[b]{2}{*}{ Reference } & \multirow[b]{2}{*}{ Type of study } & \multirow{2}{*}{$\begin{array}{c}\text { Dose of } \\
\text { EPA+DHA }(g / d)\end{array}$} & \multirow{2}{*}{$\begin{array}{l}\text { Duration } \\
\text { (weeks) }\end{array}$} & \multicolumn{3}{|c|}{ Subjects } & \multirow{2}{*}{$\begin{array}{l}\text { Stimulus } \\
\text { used }\end{array}$} & \multirow[b]{2}{*}{ Cytokines studied } & \multirow[b]{2}{*}{ Effect seen $\dagger$} \\
\hline & & & & $n$ & Gender & Age (years) & & & \\
\hline Trebble et al. $(2003 b)$ & Open, parallel & $0.3(0.2+0.1)$ & 4 & 16 & $\mathrm{M}$ & mean 30 & Con A & IFN- $\gamma$, IL-4 & None \\
\hline Wallace et al. (2003) & $\mathrm{DB}, \mathrm{PC}, \mathrm{R}$, parallel & $0.4(0.1+0.3)$ & 12 & 8 & $\mathrm{M}$ & $18-39$, mean 25 & Con A & IL-2, IFN- $\gamma$, IL-4, IL-10 & None \\
\hline Thies et al. (2001c) & $\mathrm{DB}, \mathrm{PC}, \mathrm{R}$, parallel & $0.7 \mathrm{DHA}$ & 12 & 8 & $M+F$ & $58-71$, mean 65 & Con A & IL-2, IFN- $\gamma$ & None \\
\hline Kew et al. (2003) & $\mathrm{DB}, \mathrm{PC}, \mathrm{R}$, parallel & $0.77(0.3+0.47)$ & 24 & 30 & $M+F$ & 25-72, mean 52 & Con A & IL-2, IFN- $\gamma$, IL-4 & None \\
\hline Miles et al. $(2004 b)$ & $\mathrm{DB}, \mathrm{PC}, \mathrm{R}$, parallel & $\begin{array}{l}0.8(0.6+0.2)+0.6 \\
\text { GLA }+2 \cdot 0 \text { ALA + } 0.7 \text { STA }\end{array}$ & 12 & $8-12$ & M & 21-44, mean 32 & Con A & IL-2, IFN- $\gamma$, IL-4, IL-10 & None \\
\hline Wallace et al. (2003) & $\mathrm{DB}, \mathrm{PC}, \mathrm{R}$, parallel & $0.9(0.3+0.6)$ & 12 & 8 & $\mathrm{M}$ & $18-39$, mean 25 & Con A & IL-2, IFN- $\gamma$, IL-4, IL-10 & None \\
\hline Thies et al. (2001c) & $\mathrm{DB}, \mathrm{PC}, \mathrm{R}$, parallel & $1.0(0.7+0.3)$ & 12 & 7 & $M+F$ & $60-68$, mean 62 & Con A & $\mathrm{IL}-2, \mathrm{IFN}-\gamma$ & None \\
\hline Trebble et al. (2003b) & Open, parallel & $1.0(0.7+0.3)$ & 4 & 16 & $\mathrm{M}$ & mean 30 & Con A & IFN- $\gamma$, IL-4 & None \\
\hline Miles et al. (2004b) & $\mathrm{DB}, \mathrm{PC}, \mathrm{R}$, parallel & $\begin{array}{l}1 \cdot 1(0 \cdot 8+0 \cdot 3)+0 \cdot 8 \\
\text { GLA }+1 \cdot 3 \text { ALA + } 0 \cdot 4 \text { STA }\end{array}$ & 12 & $8-12$ & $\mathrm{M}$ & 21-44, mean 32 & Con A & IL-2, IFN- $\gamma$, IL-4, IL-10 & None \\
\hline Miles et al. (2004b) & $\mathrm{DB}, \mathrm{PC}, \mathrm{R}$, parallel & $1 \cdot 6(1 \cdot 1+0 \cdot 5)+1 \cdot 0$ GLA & 12 & $8-12$ & M & 21-44, mean 32 & Con A & IL-2, IFN- $\gamma$, IL-4, IL-10 & None \\
\hline Miles et al. (2006) & $\mathrm{DB}, \mathrm{PC}, \mathrm{R}$, parallel & $1.65(1.35+0.3)$ & 12 & 23 & $\mathrm{M}$ & 18-42, mean 24 & Con A & IL-2, IFN- $\gamma$, IL-4, IL-10 & None \\
\hline Kew et al. (2003) & $\mathrm{DB}, \mathrm{PC}, \mathrm{R}$, parallel & $1 \cdot 7(0 \cdot 7+1 \cdot 0)$ & 24 & 30 & $M+F$ & 25-72, mean 54 & Con A & IL-2, IFN- $\gamma$, IL-4 & None \\
\hline Wallace et al. (2003) & $\mathrm{DB}, \mathrm{PC}, \mathrm{R}$, parallel & $1.9(0.5+1 \cdot 4)$ & 12 & 8 & $\mathrm{M}$ & 18-39, mean 22 & Con A & IL-2, IFN- $\gamma$, IL-4, IL-10 & None \\
\hline Trebble et al. (2003b) & Open, parallel & $2 \cdot 0(1 \cdot 3+0 \cdot 7)$ & 4 & 16 & $\mathrm{M}$ & mean 30 & Con A & IFN- $\gamma$, IL-4 & $\begin{array}{l}\text { IFN- } \gamma, 220 \% \uparrow ; \\
\text { IL-4, none }\end{array}$ \\
\hline Virella et al. (1991) & $\mathrm{DB}, \mathrm{PC}$ & $2 \cdot 4$ EPA & 6 & 4 & M & $24-48$ & $\begin{array}{l}\text { PHA } \\
\text { PWM }\end{array}$ & $\begin{array}{l}\mathrm{IL}-2 \\
\mathrm{IL}-2\end{array}$ & $\begin{array}{l}\downarrow 59 \% \\
\downarrow 45 \%\end{array}$ \\
\hline Meydani et al. (1991) & Open, parallel & $2 \cdot 4(1 \cdot 7+0 \cdot 7)$ & 12 & 5 & $\mathrm{~F}$ & 23-33, mean 27 & $\begin{array}{l}\text { Con A } \\
\text { PHA }\end{array}$ & $\begin{array}{l}\text { IL-2, } \\
\text { IL-2 }\end{array}$ & $\begin{array}{l}\text { None } \\
\text { None }\end{array}$ \\
\hline Meydani et al. (1991) & Open, parallel & $2 \cdot 4(1 \cdot 7+0 \cdot 7)$ & 12 & 6 & $\mathrm{~F}$ & 51-68, mean 61 & $\begin{array}{l}\text { Con A } \\
\text { PHA }\end{array}$ & $\begin{array}{l}\mathrm{IL}-2 \\
\mathrm{IL}-2\end{array}$ & $\begin{array}{l}\text { None } \\
\text { None }\end{array}$ \\
\hline Miles et al. (2004b) & $\mathrm{DB}, \mathrm{PC}, \mathrm{R}$, parallel & $3.0(2.1+0.9)$ & 12 & 10 & $M$ & 21-44, mean 32 & Con A & IL-4, IL-10 & None \\
\hline Miles et al. (2006) & $\mathrm{DB}, \mathrm{PC}, \mathrm{R}$, parallel & $3 \cdot 3(2 \cdot 7+0 \cdot 6)$ & 12 & 23 & M & $18-42$, mean 25 & Con A & IL-2, IFN- $\gamma$, IL-4, IL-10 & $\begin{array}{l}\text { IL-4, } \uparrow 81 \% \text {; IL-2, } \\
\text { IFN- } \gamma, \text { IL-10, none }\end{array}$ \\
\hline Yaqoob et al. (2000) & $\mathrm{DB}, \mathrm{PC}, \mathrm{R}$, parallel & $3 \cdot 3(2 \cdot 1+1 \cdot 1)$ & 12 & 8 & $M+F$ & mean 39 & Con A & IL-2, IFN- $\gamma$, IL-10 & None \\
\hline Endres et al. (1993) & Open, non-parallel & $4 \cdot 7(2 \cdot 8+1 \cdot 9)$ & 6 & 9 & $\mathrm{M}$ & $21-39$, mean 28 & PHA & IL-2 & None \\
\hline Kew et al. (2004) & $\mathrm{DB}, \mathrm{PC}, \mathrm{R}$, parallel & $4 \cdot 7$ EPA & 4 & 14 & $M+F$ & 23-65, mean 46 & Con A & IL-2, IL-4, IL-5, IL-10, IFN- $\gamma$ & None \\
\hline Kew et al. (2004) & $\mathrm{DB}, \mathrm{PC}, \mathrm{R}$, parallel & $4.9 \mathrm{DHA}$ & 4 & 14 & $M+F$ & 23-65, mean 45 & Con A & IL-2, IL-4, IL-5, IL-10, IFN- $\gamma$ & None \\
\hline Miles et al. (2006) & $\mathrm{DB}, \mathrm{PC}, \mathrm{R}$, parallel & $4.95(4.05+0.9)$ & 12 & 23 & M & 18-42, mean 24 & Con A & IL-2, IFN- $\gamma$, IL-4, IL-10 & $\begin{array}{l}\text { IL-4,个 } 62 \% ; \text { IL-2, } \\
\text { IFN- } \gamma, \text { IL-10, none }\end{array}$ \\
\hline Gallai et al. (1995) & Open & $5 \cdot 2(3 \cdot 1+2 \cdot 1)$ & 26 & 15 & $M+F$ & $20-50$ & $\begin{array}{l}\text { PHA } \\
\text { Con A }\end{array}$ & $\begin{array}{l}\text { IL-2 } \\
\text { IFN- } \gamma\end{array}$ & $\begin{array}{l}\downarrow 20 \% \\
\downarrow 40 \%\end{array}$ \\
\hline
\end{tabular}


subjects (Meydani et al. 1993; Thies et al. 2001c; Bechoua et al. 2003) that report decreased lymphocyte proliferation associated with increased EPA and DHA intake. It would be useful to conduct a well-powered study comparing the effects of long-chain n-3 PUFA on T lymphocyte proliferation in young and older subjects.

\section{Effects of EPA and DHA on natural killer cell activity}

Four studies have examined the effects of long-chain $n-3$ PUFA on NK cell activity in healthy human volunteers. In all cases this variable has been measured as activity within purified peripheral blood mononuclear cells. Thies et al. (2001b) have reported inhibition of NK cell activity by $1.0 \mathrm{~g} \mathrm{EPA}+\mathrm{DHA} / \mathrm{d}$ but no effect of $0.7 \mathrm{~g} \mathrm{DHA} / \mathrm{d}$ in elderly subjects. Kelley et al. (1999) have reported inhibition of NK cell activity following $6 \mathrm{~g}$ DHA/d in young males. In contrast, Yaqoob et al. (2000) have found no effect of $3.3 \mathrm{~g} \mathrm{EPA}+\mathrm{DHA} / \mathrm{d}$ on NK cell activity in a mixed group of healthy subjects. Moreover, a recent study (Miles et al. 2006) has identified a trend toward increased NK cell activity with increased EPA and DHA consumption in young males. Taken together, the effects of long-chain $n-3$ PUFA on NK cell activity remain unclear and the inconsistency has only increased with this recent report. Previous suggestions that 'high' but not 'low' doses of DHA can decrease NK cell activity (Kelley et al. 1999; Thies et al. 2001b) and that cells from older subjects might be more susceptible to the effects of EPA and DHA than those of young subjects (Calder, 2001a) are not rejected by the recent data. Again, it would be useful to conduct a well-powered study comparing the effects of long-chain $n$ 3 PUFA on NK cell activity in young and older subjects.

\section{Effects of EPA and DHA on ex vivo cytokine production by $T$-cells}

Twelve healthy volunteer studies have reported the effects of long-chain $n$-3 PUFA on ex vivo cytokine production by lymphocytes (Table 2). Again the most-frequent stimulus used to elicit cyokine production has been a T-cell mitogen, particularly Con A. The supplementation level in these studies ranged from $0 \cdot 3$ to $5 \cdot 2 \mathrm{~g} \mathrm{EPA}+\mathrm{DHA} / \mathrm{d}$ in a total of twenty-five treatment cohorts. Seven studies with a double-blind placebo-controlled randomised parallel design accounted for seventeen treatment cohorts. Most studies measured concentrations of one or more of the cytokines IL-2, IFN- $\gamma$, IL- 4 and IL-10 in supernatant fractions from stimulated peripheral blood mononuclear cell cultures. IL-4 is a cytokine produced by Th-2-type lymphocytes, whereas IL- 2 and IFN- $\gamma$ are produced by Th-1-type lymphocytes (Mosmann \& Sad, 1996) and IL-10 is the product of regulatory T-cells.

In the lower dose ranges $(<2 \cdot 0 \mathrm{~g} / \mathrm{d})$ no significant effects of EPA+DHA on the production of any cytokine have been reported (Table 2). However, Trebble et al. (2003b) have found a dose-responsive increase in IFN- $\gamma$ production from baseline that reached significance $(P<0.05)$ at $2.0 \mathrm{~g}$ $\mathrm{EPA}+\mathrm{DHA} / \mathrm{d}$. A non-significant trend towards increased IL-4 production was also noted in this study, and IL-4 production was found to be positively correlated with
IFN- $\gamma$ production. A positive correlation between the production of both cytokines and concentrations of EPA in plasma phosphatidylcholine was also reported. Miles et al. (2006) have reported significantly $(P<0 \cdot 05)$ increased IL-4 production from baseline at EPA + DHA intakes of 3.3 and $4.95 \mathrm{~g} / \mathrm{d}$ (Fig. 2(c)), but these increases were not different from placebo values (Table 2). In contrast with the finding by Trebble et al. (2003b), at higher EPA+DHA intakes decreased production of IFN- $\gamma$ and IL-2, another Th-1 cytokine, has been reported in some studies. Virella et al. (1991) have reported decreased IL-2 production following $2.4 \mathrm{~g} \mathrm{EPA} / \mathrm{d}$. Meydani et al. (1991), using a supplement of the same dose level, have found decreased IL-2 production that approaches significance $(P=0.057)$ in older, but not young, women. Gallai et al. (1995) have reported a decrease in PHA-induced IL-2 production as well as Con A-induced IFN- $\gamma$ production following supplementation with $5 \cdot 2 \mathrm{~g}$ EPA +DHA/d. Trebble et al. (2003b) have proposed a dose-response relationship between EPA and DHA intake and cytokine production by Th- 1 type cells; increasing production at intakes of $\leq 2 \mathrm{~g} / \mathrm{d}$ for $\leq 4$ weeks and an inhibitory effect at higher intakes or after longer periods of similar intakes. On the other hand, all studies that used a double-blind placebo-controlled randomised parallel design, covering a dose range from 0.4 to $4.95 \mathrm{~g}$ $\mathrm{EPA}+\mathrm{DHA} / \mathrm{d}$ and seventeen dose levels, have failed to show significant effects on the production of Th-1-type cytokines (Table 2). In all but one study post supplementation IFN- $\gamma$ and IL-2 concentrations were found to be similar to those in controls as well as at baseline (Yaqoob et al. 2000; Thies et al. 2001c; Kew et al. 2003, 2004; Wallace et al. 2003; Miles et al. 2006). Miles et al. $(2004 a)$ have found a generalised and significant $(P<0 \cdot 05)$ increase in the production of all measured $\mathrm{T}$ lymphocytederived cytokines (IL-2, IL-4, IL-10, IFN- $\gamma$ ) from baseline. This response was also found in the placebo group, implying a causal factor different from EPA and DHA intake. There are no studies that report significant effects of long-chain $n$-3 PUFA supplementation on IL-10 production. Fig. 2(a,b,c,d) indicate that the non-significant percentage changes from baseline observed in these studies were generally small and not consistent in direction. These observations suggest that the observed effects of EPA and DHA on the production of T-cell cytokines may be a result of factors that are uncorrected by the limitations of open studies. For instance, changes in outcomes reported may occur over time. The observation by Kew et al. (2004) is noteworthy in that it shows that in the absence of effects on cytokines CD69 expression, a marker of T-cell activation, is reduced by $4.9 \mathrm{~g}$ DHA/d but not by $4.7 \mathrm{~g}$ $\mathrm{EPA} / \mathrm{d}$. This result suggests that ex vivo cytokine response to Con A may not be the most-sensitive marker of T-cell function. In addition, this result suggests that DHA may be more potent in modulating $\mathrm{T}$-cell function than EPA.

In conclusion, the studies conducted so far on the effects of dietary long-chain $n$-3 PUFA on lymphocyte function reflected by cytokine production are highly inconsistent and therefore inconclusive. If there is any response at all, a dose level of $\geq 2 \mathrm{~g} \mathrm{EPA}+\mathrm{DHA} / \mathrm{d}$ is required to significantly affect cytokine production by $\mathrm{T}$-cells. The 


\begin{tabular}{|c|c|c|c|c|c|c|c|c|}
\hline \multirow[b]{2}{*}{ Reference } & \multirow[b]{2}{*}{ Type of study } & \multirow{2}{*}{$\begin{array}{c}\text { Dose of } \\
\text { EPA+DHA }(g / d)\end{array}$} & \multirow{2}{*}{$\begin{array}{l}\text { Duration } \\
\text { (weeks) }\end{array}$} & \multicolumn{3}{|c|}{ Subjects } & \multirow{2}{*}{$\begin{array}{l}\text { Cytokines } \\
\text { studied } †\end{array}$} & \multirow[b]{2}{*}{ Effect seen $\ddagger$} \\
\hline & & & & $n$ & Gender & Age (years) & & \\
\hline Trebble et al. (2003a) & Open, parallel & $0.3(0.2+0.1)$ & 4 & 16 & M & mean 30 & IL-6, TNF $\alpha$ & IL-6, $\downarrow 51 \% ;$ TNF $\alpha, \downarrow 48 \%$ \\
\hline Wallace et al. (2003) & $\mathrm{DB}, \mathrm{PC}, \mathrm{R}$, parallel & $0.4(0.1+0.3)$ & 12 & 8 & M & 18-39, mean 25 & IL-1 $\beta$, TNF $\alpha$, IL-6 & None \\
\hline Hawkes et al. (2002) & $\begin{array}{l}\mathrm{DB}, \mathrm{PC}, \mathrm{R}, \\
\text { prospective }\end{array}$ & $0.4(0.1+0.3)$ & 4 & 26 & $\mathrm{~F}$ & $>18$, mean 30 & IL-1 $\beta$, IL-6, TNF $\alpha$ & None \\
\hline Schmidt et al. (1996) & $\mathrm{DB}, \mathrm{PC}, \mathrm{R}$ & $0.6(0.34+0.19)$ & 12 & 16 & $M+F$ & $24-52$ & IL-1 $\beta$, IL-6, TNF $\alpha$ & None \\
\hline Hawkes et al. (2002) & $\begin{array}{l}\mathrm{DB}, \mathrm{PC}, \mathrm{R}, \\
\text { prospective }\end{array}$ & $0 \cdot 7(0 \cdot 1+0 \cdot 6)$ & 4 & 29 & $\mathrm{~F}$ & $>18$, mean 30 & IL-1 $\beta$, IL-6, TNF $\alpha$ & None \\
\hline Thies et al. (2001a) & $\mathrm{DB}, \mathrm{PC}, \mathrm{R}$, parallel & $0.7 \mathrm{DHA}$ & 12 & 8 & $M+F$ & $58-71$, mean 65 & IL-1 $\beta$, IL-6, TNF $\alpha$ & None \\
\hline Kew et al. (2003) & $\mathrm{DB}, \mathrm{PC}, \mathrm{R}$, parallel & $0.77(0.3+0.47)$ & 24 & 30 & $M+F$ & 25-72, mean 52 & IL-1 $\beta$, IL-6, TNF $\alpha$, IL-10 & None \\
\hline Miles et al. (2004b) & $\mathrm{DB}, \mathrm{PC}, \mathrm{R}$, parallel & $\begin{array}{c}0.8(0 \cdot 6+0 \cdot 2)+0.6 \\
\text { GLA }+2 \cdot 0 \\
\text { ALA }+0.7 \text { STA }\end{array}$ & 12 & $8-12$ & M & $21-44$, mean 32 & IL-1 $\beta$, TNF $\alpha$ & None \\
\hline Wallace et al. (2003) & $\mathrm{DB}, \mathrm{PC}, \mathrm{R}$, parallel & $0.9(0.3+0.6)$ & 12 & 8 & M & 18-39, mean 25 & $\mathrm{IL}-1 \beta, \mathrm{TNF} \alpha, \mathrm{IL}-6$ & IL-1 $\beta$, TNF $\alpha$, none; IL- $6, \downarrow 45 \%$ \\
\hline Thies et al. (2001a) & $\mathrm{DB}, \mathrm{PC}, \mathrm{R}$, parallel & $1.0(0.7+0.3)$ & 12 & 7 & $M+F$ & $60-68$, mean 62 & IL-1 $\beta$, IL-6, TNF $\alpha$ & None \\
\hline Trebble et al. (2003a) & Open, parallel & $1.0(0.7+0.3)$ & 4 & 16 & M & mean 30 & IL-6, TNF $\alpha$ & IL-6, $\downarrow 84 \% ;$ TNF $\alpha, \downarrow 66 \%$ \\
\hline Blok et al. (1997) & $\mathrm{DB}, \mathrm{PC}, \mathrm{R}$, parallel & $1.0(0.8+0.2)$ & 52 & 15 & M & 21-87, mean 56 & IL-1 $\beta$, TNF $\alpha$ & None \\
\hline Miles et al. (2004b) & $\mathrm{DB}, \mathrm{PC}, \mathrm{R}$, parallel & $\begin{array}{c}1 \cdot 1(0 \cdot 8+0 \cdot 3)+0 \cdot 8 \\
\text { GLA }+1 \cdot 3 \\
\text { ALA }+0 \cdot 4 \text { STA }\end{array}$ & 12 & $8-12$ & M & $21-44$, mean 32 & $\mathrm{IL}-1 \beta, \mathrm{TNF} \alpha$ & None \\
\hline Meydani et al. (1993) & Open, PC, parallel & $1 \cdot 24$ & 24 & 10 & $\mathrm{~F}$ & $>40$ mean 65 & IL-1 $\beta$, IL-6, TNF $\alpha$ & $\begin{array}{l}\text { IL- } 1 \beta, \downarrow 50 \% \text {; IL-6, none; } \\
\quad \text { TNF } \alpha, \downarrow 49 \%\end{array}$ \\
\hline Ciubotaru et al. (2003) & $\mathrm{DB}, \mathrm{PC}, \mathrm{R}$ & $1 \cdot 1(0 \cdot 6+0 \cdot 5)$ & 5 & 10 & $\mathrm{~F}$ & mean 60 & IL-6 & IL-6, $\downarrow 10 \%$ \\
\hline Cooper et al. (1993) & Open & $1.3(0.8+0.5)$ & $6-8$ & $6-8$ & $M+F$ & $18-36$ & IL1 $\beta$, IL-6, TNF $\alpha$ & $\begin{array}{l}\text { IL1 } \beta, \downarrow 85 \% ; \text { IL-6, } \downarrow 90 \% ; \\
\text { TNF } \alpha, \text { none }\end{array}$ \\
\hline Vega-Lopez et al. (2004) & $\mathrm{DB}, \mathrm{PC}, \mathrm{R}$, parallel & $1.5(0.6+0.9)$ & 12 & 20 & $M+F$ & 20-55, mean 30 & $\begin{array}{l}\text { MCP-1-induced IL-1 } \beta \text {, } \\
\text { IL-6, TNF } \alpha\end{array}$ & None \\
\hline Miles et al. (2004b) & $\mathrm{DB}, \mathrm{PC}, \mathrm{R}$, parallel & $1 \cdot 6(1 \cdot 1+0 \cdot 5)+1 \cdot 0 \mathrm{GLA}$ & 12 & $8-12$ & M & $21-44$, mean 32 & IL-1 $\beta$, TNF $\alpha$ & None \\
\hline Molvig et al. (1991) & Open, PC & $1 \cdot 6(1+0 \cdot 6)$ & 7 & 9 & $M+F$ & mean 27 & IL-1 $\beta$, TNF $\alpha$ & None \\
\hline \multirow[t]{2}{*}{ Rees et al. (2006) } & $\mathrm{DB}, \mathrm{PC}, \mathrm{R}$, parallel & $1 \cdot 65(1 \cdot 35+0 \cdot 3)$ & 12 & 23 & M & 18-42, mean 24 & IL-1 $\beta$, IL-6, TNF $\alpha$ & None \\
\hline & $\mathrm{DB}, \mathrm{PC}, \mathrm{R}$, parallel & $1 \cdot 65(1.35+0 \cdot 3)$ & 12 & 15 & M & 53-70, mean 61 & IL-1 $\beta$, IL-6, TNF $\alpha$ & None \\
\hline Kew et al. (2003) & $\mathrm{DB}, \mathrm{PC}, \mathrm{R}$, parallel & $1 \cdot 7(0 \cdot 7+1 \cdot 0)$ & 24 & 30 & $M+F$ & 25-72, mean 54 & IL-1 $\beta$, IL-6, IL-10, TNF $\alpha$ & None \\
\hline Grimble et al. (2002) & Open & $1 \cdot 8$ & 12 & 37 & M & 20-57, mean 28 & TNF $\alpha$ & $\begin{array}{l}\downarrow 63 \% \text { or } \uparrow 161 \% \text { genotype } \\
\text { dependent }\end{array}$ \\
\hline Wallace et al. (2003) & $\mathrm{DB}, \mathrm{PC}, \mathrm{R}$, parallel & $1.9(0.5+1.4)$ & 12 & 8 & M & 18-39, mean 22 & $\mathrm{IL}-1 \beta, \mathrm{TNF} \alpha, \mathrm{IL}-6$ & IL-1 $\beta$, TNF $\alpha$, none; IL-6, $\downarrow 19 \%$ \\
\hline Blok et al. (1997) & $\mathrm{DB}, \mathrm{PC}, \mathrm{R}$, parallel & $1.9(1.6+0.3)$ & 52 & 15 & M & $21-87$, mean 56 & IL-1 $\beta$, TNF $\alpha$ & None \\
\hline Trebble et al. (2003a) & Open, parallel & $2 \cdot 0(1 \cdot 3+0 \cdot 7)$ & 4 & 16 & M & mean 30 & IL-6, TNF $\alpha$ & IL-6, $\downarrow 79 \% ;$ TNF $\alpha, \downarrow 59 \%$ \\
\hline Ciubotaru et al. (2003) & $\mathrm{DB}, \mathrm{PC}, \mathrm{R}$ & $2 \cdot 2(1 \cdot 2+1 \cdot 0)$ & 5 & 10 & $\mathrm{~F}$ & mean 60 & $\mathrm{IL}-6$ & None \\
\hline \multirow[t]{2}{*}{ Meydani et al. (1991) } & Open, parallel & $2 \cdot 4(1 \cdot 7+0 \cdot 7)$ & 12 & 5 & $\mathrm{~F}$ & 23-33, mean 27 & IL-1 $\beta$, IL-6, TNF $\alpha$ & $\begin{array}{l}\text { IL-1 } \beta, \downarrow 43 \% ; \text { IL-6, } \downarrow 22 \% ; \\
\quad \text { TNF } \alpha, \downarrow 45 \%\end{array}$ \\
\hline & Open, parallel & $2 \cdot 4(1 \cdot 7+0 \cdot 7)$ & 12 & 6 & $\mathrm{~F}$ & $51-68$, mean 61 & IL-1 $\beta$, IL-6, TNF $\alpha$ & $\begin{array}{l}\text { IL- } 1 \beta, \downarrow 85 \% ; \text { IL-6, } \downarrow 60 \% ; \\
\quad \text { TNF } \alpha, \downarrow 66 \%\end{array}$ \\
\hline Wu et al. (2004) & $\mathrm{DB}, \mathrm{PC}, \mathrm{R}$ & $2 \cdot 5(1 \cdot 5+1 \cdot 0)$ & 12 & 10 & $M+F$ & $>65$ & $\begin{array}{l}\mathrm{IL}-1 \beta \\
\text { Con A- and PHA- } \\
\text { induced IL-6, TNF } \alpha\end{array}$ & $\begin{array}{l}\text { None } \\
\text { IL-6, } \downarrow ; \text { IL-6, NS; TNF } \alpha, \text { NS; } \\
\quad \text { TNF } \alpha, \downarrow \text { following PHA }\end{array}$ \\
\hline Caughey et al. (1996) & Open, parallel & $2 \cdot 7(1 \cdot 6+1 \cdot 1)$ & 4 & 13 & $M+F$ & $24-44$ & IL-1 $\beta$, TNF $\alpha$ & IL-1 $\beta, \downarrow 80 \% ;$ TNF $\alpha, \downarrow 74 \%$ \\
\hline Blok et al. (1997) & $\mathrm{DB}, \mathrm{PC}, \mathrm{R}$, parallel & $2.9(2.4+0.5)$ & 52 & 14 & $\mathrm{M}$ & 21-87, mean 56 & IL-1 $\beta$, TNF $\alpha$ & None \\
\hline
\end{tabular}




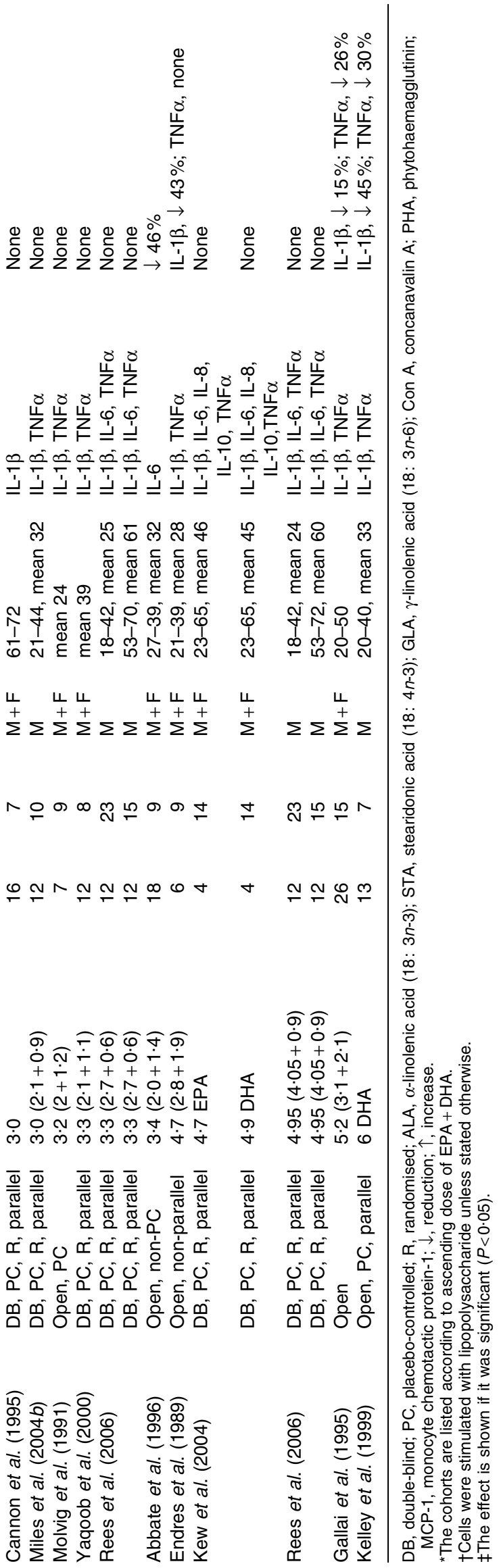

concept that supplementation of EPA might influence the Th- $1 v$. Th-2 balance in favour of the Th- 1 phenotype via inhibition of $\mathrm{PGE}_{2}$ is not supported by the available data. Particularly, the observation of a possible concomitant dose-dependent decrease in $\mathrm{PGE}_{2}$ and an increase in IL-4 production (Trebble et al. 2003b) is in contrast with this concept. If any effect on Th cell cytokine production is real, another mechanism is more likely underlying this effect.

\section{Effects of EPA and DHA on ex vivo cytokine production by monocytes}

The largest body of evidence on immunomodulatory effects of long-chain $n$-3 PUFA in healthy subjects derives from studies on inflammatory cytokines. In general, these studies measured concentrations of one or more of the cytokines IL-1 $\beta$, TNF $\alpha$ and IL- 6 produced by monocytes in response to ex vivo stimulation with LPS. LPS selectively stimulates monocyte function because these cells express CD14, the LPS receptor. Studies typically used purified peripheral blood mononuclear cells, although some studies used isolated monocytes. Twenty-four studies covering a dose range from 0.3 to $6 \mathrm{~g} \mathrm{EPA}+\mathrm{DHA} / \mathrm{d}$ in forty-six treatment cohorts were identified (Table 3). At least twenty-five cohorts in eleven studies were investigated in a double-blind placebo-controlled randomised parallel study design (Table 3 ).

The results of the large number of studies are not fully consistent. There are no studies that report that long-chain $n-3$ PUFA significantly increase production of IL-1 $\beta$, TNF $\alpha$ or IL-6 in response to ex vivo stimulation with LPS. A substantial number of studies have found decreased production of one or more inflammatory cytokine, but a larger number of studies have failed to find significant effects (Table 3). In ten of twenty-eight treatment cohorts reporting IL-6 production a significant $(P<0 \cdot 05)$ decrease was reported (Fig. 3(c)). A significant $(P<0 \cdot 05)$ decrease in IL-6 responses to LPS stimulation was found at $\mathrm{EPA}+\mathrm{DHA}$ doses ranging from 0.3 to $3.4 \mathrm{~g} / \mathrm{d}$. Trebble et al. (2003a) have reported a negative but 'U-shaped' dose-response relationship between long-chain $n$-3 PUFA intake and IL- 6 production in an open uncontrolled study, with a maximum inhibition demonstrated at a supplementary intake of $1.0 \mathrm{~g} / \mathrm{d}$. Wallace et al. (2003) have studied similar dose levels in a controlled blinded parallel study and have found a very similar result. On the other hand, other blinded parallel studies (Thies et al. 2001a; Kew et al. 2003, 2004; Rees et al. 2006) have not found decreased IL- 6 production within the EPA+DHA dose range of $1-2 \mathrm{~g} / \mathrm{d}$ or at higher doses. IL- $1 \beta$ production was found to be decreased at EPA + DHA intake levels from $1 \cdot 24 \mathrm{~g} / \mathrm{d}$ to $6 \mathrm{~g} / \mathrm{d}$ in eight of thirty-five of the cohorts in which it was measured,. A striking similarity of these treatment cohorts is that all were part of open studies. A similar picture emerges from the studies on $\mathrm{TNF} \alpha$ production; in nine of thirty-nine treatment cohorts a significant $(P<0.05)$ decrease in LPS-induced TNF $\alpha$ production was reported, all were part of open studies. The $\mathrm{EPA}+\mathrm{DHA}$ intake levels that were associated with inhibition of $\mathrm{TNF} \alpha$ production varied from $0.3 \mathrm{~g} / \mathrm{d}$ to $6 \mathrm{~g} / \mathrm{d}$. 


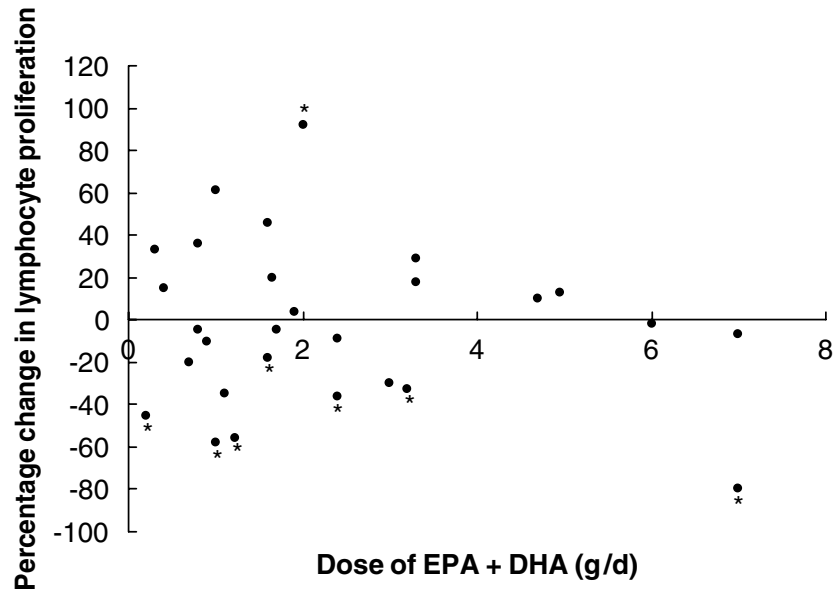

Fig. 1. Relationship between the daily intake of EPA and DHA and ex vivo lymphocyte proliferation response in healthy human subjects. Each data point represents the percentage change in mitogen-induced lymphocyte proliferation observed in a cohort in an $E P A+D H A$ supplementation study. Percentage changes were reported to be significantly different from their controls: ${ }^{\star} P<0.05$. Data are taken from the studies listed in Table 1.

The study by Caughey et al. (1996) indicates a strong inverse dose-response relationship between mononuclear cell EPA content and production of IL-1 $\beta$ and TNFo. This earlier report was followed by several more recent reports of studies that have failed to find the same direct correlations between increased EPA concentrations in mononuclear cells and production of IL-1 $\beta$ and TNF $\alpha$. Trebble et al. (2003a) have reported a negative but 'U-shaped' dose-response relationship between long-chain $n$-3 PUFA intake and TNF $\alpha$ production, with a maximum inhibition demonstrated at a supplementary EPA + DHA intake of $1.0 \mathrm{~g} / \mathrm{d}$. Unfortunately, no EPA concentrations in peripheral blood mononuclear cells were reported in this study. Miles et al. (2004a) have found a dose-dependent rise in EPA concentrations in blood mononuclear cells with intake levels $\leq 3 \mathrm{~g} \mathrm{EPA}+\mathrm{DHA} / \mathrm{d}$ but with no concomitant change in IL-6 and TNF $\alpha$ production. Yaqoob et al. (2000) have found a fourfold rise in blood mononuclear cell EPA concentration following an intake of $3.3 \mathrm{~g} \mathrm{EPA}+\mathrm{DHA} / \mathrm{d}$ resulting in only a small non-significant decrease in IL-6 and TNF $\alpha$ production by those cells. A recent study (Rees et al. 2006) that used four intake levels of $\leq 4.95 \mathrm{~g}$ $\mathrm{EPA}+\mathrm{DHA} / \mathrm{d}$ has found a dose-dependent increase in EPA concentrations and in EPA:ARA in mononuclear cell phospholipids. This shift in eicosanoid precursors was shown to be correlated with a stepwise decline in $\mathrm{PGE}_{2}$ production by mononuclear cells stimulated with LPS and in neutrophil respiratory burst, but was not found to be correlated with changes in IL- $1 \beta$ and TNF $\alpha$ production by mononuclear cells. Fig. 3(a,b) show the percentage changes from baseline in IL- $1 \beta$ and TNF $\alpha$ production from all studies and illustrate the distribution of the significant $(P<0 \cdot 05)$ changes over the entire EPA + DHA dose range studied. The results do not confirm the presence of a doseresponse relationship between long-chain $n-3$ PUFA intake and inhibition of IL- $1 \beta$ and TNF $\alpha$ production. The different observations made by Caughey et al. (1996) and in some later reports may be explained by differences in the age of study subjects, greater amounts of $\alpha$-tocopherol in the capsules used in the more recent studies and differences in the precise nature of samples in which cytokine measurements were made (Calder, 2001a), but the reason for the differences is not yet clear (Rees et al. 2006). One other factor recently identified by Grimble et al. (2002) is polymorphisms in genes affecting cytokine production. These authors have shown that the effect of dietary fish oil on TNF $\alpha$ production by human mononuclear cells is dependent on the nature of the -308 TNF $\alpha$ and the +252 TNF $\beta$ polymorphisms.

In conclusion, a large body of available studies provides substantial evidence that the production of inflammatory cytokines in healthy subjects can be decreased by increasing intake of EPA + DHA. However, this evidence is not conclusive, as these reports are outnumbered by studies that find no significant effects of EPA +DHA, and the reason for this inconsistency is unclear. The proposed dose dependence of anti-inflammatory actions of long-chain $n-3$ PUFA is not consistently reflected in cytokine concentrations, perhaps because of low susceptibility of ex vivo cytokine production in healthy subjects to changed EPA concentrations in membrane phospholipids of monocytes and mononuclear cells. That supplemental long-chain $n-3$ PUFA do not increase the production of inflammatory cytokines in healthy subjects is highly consistent; no studies have reported such an increase. Thus, these findings in healthy subjects may serve as a rationale to supplement long-chain $n-3$ PUFA to subjects with inflammatory disorders that are (partly) caused by excessive formation of inflammatory cytokines.

\section{Intervention studies in (chronic) inflammatory conditions and disorders}

\section{Introductory comments}

Inflammatory cytokines produced by monocytes and macrophages have an important role in the regulation of the whole-body response to infection and injury. Thus, inflammation and the inflammatory response are part of the innate immune response that is normally protective to the host. However, in some inflammatory conditions and diseases the inflammatory response occurs in an uncontrolled or inappropriate manner and causes excessive damage to the host tissues and disease can ensue. A common characteristic of these conditions and diseases is excessive or inappropriate production of inflammatory mediators, including eicosanoids and cytokines. High concentrations of TNF $\alpha$, IL- $1 \beta$ and IL- 6 are particularly destructive and are implicated in chronic inflammatory diseases such as rheumatoid arthritis and inflammatory bowel diseases. Chronic overproduction of these cytokines can cause adipose tissue and muscle wasting and loss of bone mass and may account for alterations in body composition and tissue loss seen in inflammatory diseases and in cancer cachexia, which is a syndrome of progressive weight loss, anorexia and persistent erosion of host body cell mass in response to a malignant growth (Morley et al. 2006). As well as its clear and obvious association with classic inflammatory 
(a)

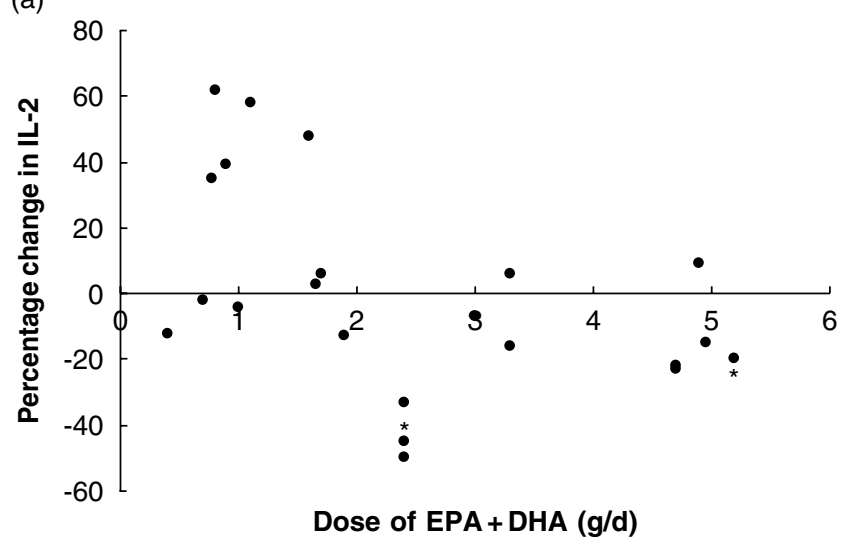

(b)

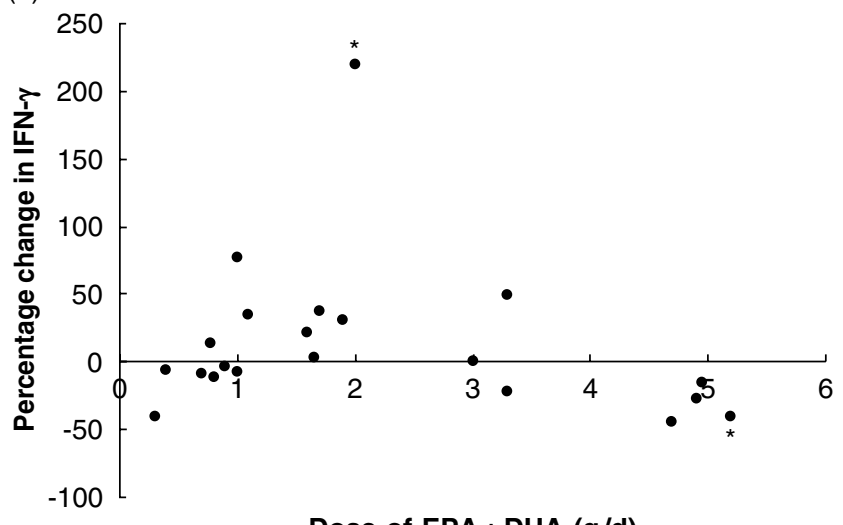

Dose of EPA + DHA (g/d)

(c)

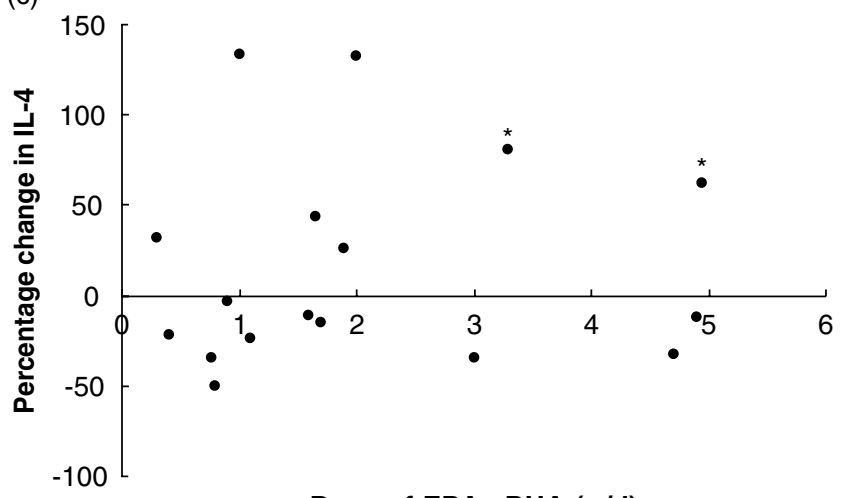

Dose of EPA + DHA (g/d)

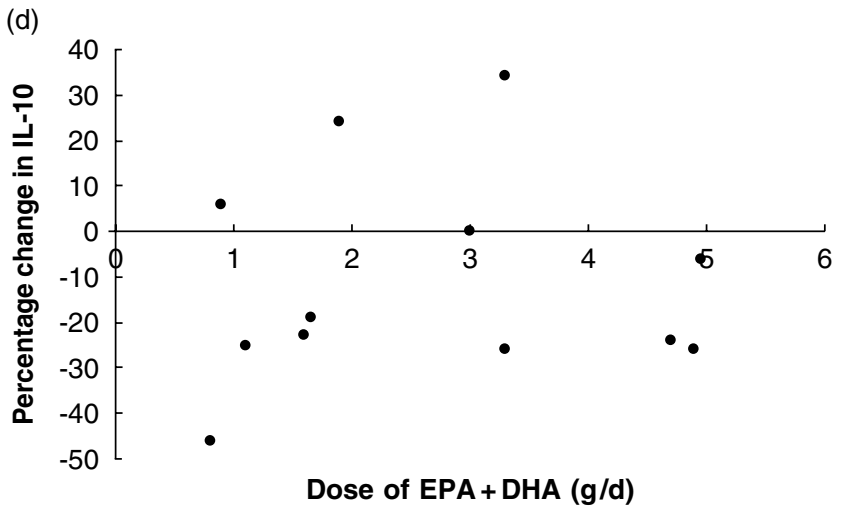

diseases, inflammation is now recognised to play an important role in the pathology of other diseases such as CVD, HIV progression and neurodegenerative diseases of aging. Additionally, the realisation that adipose tissue is a source of inflammatory cytokines has given rise to the notion that obesity, the metabolic syndrome and type 2 diabetes have an inflammatory component (Calder, 2006).

This section focuses on studies with long-chain $n-3$ PUFA in inflammatory conditions that report some of the immune markers that are most commonly studied in intervention studies in healthy volunteers rather than on disease-specific clinical outcomes (which should be considered as the most important marker of effectiveness). In addition to the immune markers reviewed in the previous section, this section reports the effects of EPA+DHA on circulating cytokines. Plasma levels of inflammatory cytokines are usually below detection level in healthy subjects but are elevated in most inflammatory conditions and are an important target of intervention because of the destructive nature of their presence in the bloodstream in excessive concentrations. The concentrations found in the blood are the net outcome of production by various cells and tissues, including infiltrated monocytes and macrophages at inflamed sites, muscle and fat tissue, and removal and degradation by various cells and tissues. Their levels reflect the in vivo pro-inflammatory state (Albers et al. 2005) and are partly linked with ex vivo production of cytokines as they are derived in part from the same type of cells. Thus, it is expected that if supplemental EPA+DHA reduces the extent to which cells are predisposed to produce excessive levels of cytokines on receiving a stimulus ex vivo, this outcome will at least partially correlate with lower in vivo concentrations of the same cytokines in conditions in which such stimuli are present.

Complex n-3 PUFA-containing nutritional products (e.g. 'immunonutrition') and parenteral supplementation of $\mathrm{EPA}+\mathrm{DHA}$-enriched emulsions have been used in patients with various inflammatory conditions. However, similar to the overview in the previous section, this section is limited to studies of oral intake of pure sources of EPA+DHA. Table 4 gives an overview of the studies addressed in this section.

\section{Cancer}

Cancer cachexia is a major factor contributing to the weakening of the already compromised immune system of patients with cancer. Cancer cachexia affects approximately $30 \%$ of patients with cancer, thus accounting for $>400000$ patients in the USA alone (Morley et al. 2006). A current belief is that the mechanism underlying cancer

Fig. 2. Relationship between the daily intake of EPA and DHA and ex vivo cytokine production by lymphocytes in healthy human subjects. Each data point represents the percentage change in mitogen-induced cytokine production (IL-2 (a), IFN- $\gamma$ (b), IL-4 (c) and IL-10 (d)) by lymphocytes observed in a cohort in an $\mathrm{EPA}+\mathrm{DHA}$ supplementation study. Percentage changes were reported to be significantly different from their controls: ${ }^{\star} P<0.05$. Data are taken from the studies listed in Table 2. 

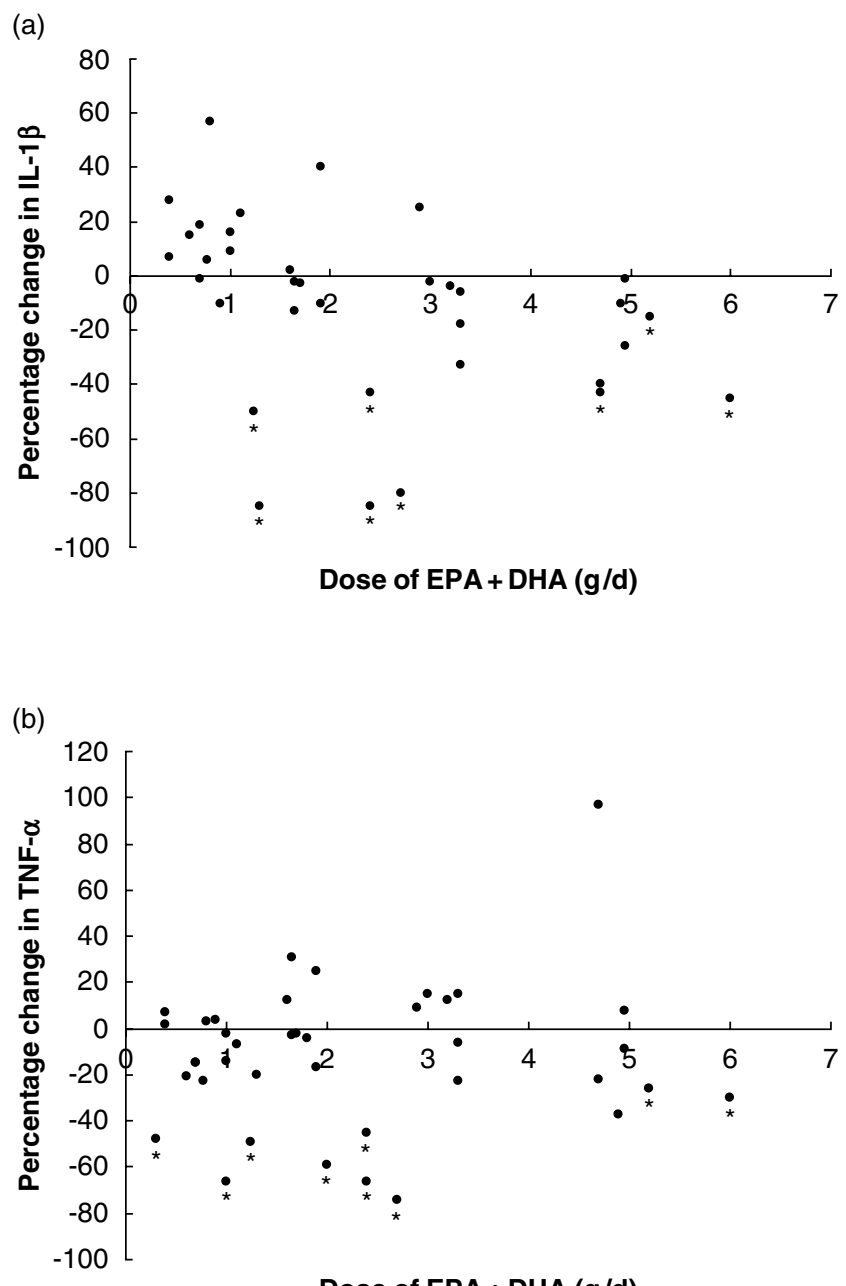

Dose of EPA + DHA (g/d)

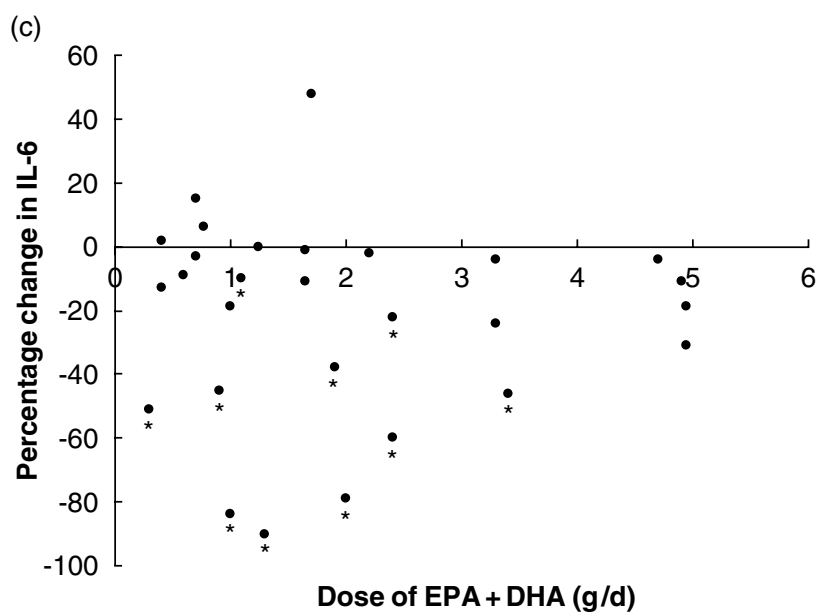

Fig. 3. Relationship between the daily intake of EPA and DHA and ex vivo cytokine production (IL-1 $\beta$ (a), TNF $\alpha$ (b) and IL-6 (c)) by monocytes in healthy human subjects. Each data point represents the percentage change in lipopolysaccharide-induced cytokine production by monocytes observed in a cohort in an EPA + DHA supplementation study. Percentage changes were reported to be significantly different from their controls: ${ }^{\star} P<0 \cdot 05$. Data are taken from the studies listed in Table 3. cachexia involves the host's production of certain cytokines, such as IL-1 $\beta$, IL-6 and TNF $\alpha$ (Todorov et al. 1996). As increased production of these cytokines may play a major role in weight loss, an important clinical question with fish oil intervention is therefore whether treatment strategies based on anti-cachexia treatment might reduce cachexia and thereby improve immune function, life expectancy and life quality. Indeed, the findings of a recent large study (Fearon et al. 2006) suggest that supplementation with EPA in cancer cachexia results in weight gain compared with placebo, particularly in gastrointestinal cancer.

The first study to report effects of fish oil supplementation on immune markers in cancer cachexia (Wigmore et al. 1997) has examined the effect of an intake level increasing from $1 \mathrm{~g} \mathrm{EPA} / \mathrm{d}$ to $6 \mathrm{~g} \mathrm{EPA} / \mathrm{d}$ during a 4-week intervention in patients with pancreatic cancer. After 4 weeks of supplementation with EPA the production of IL-6 by blood mononuclear cells was found to be significantly $(P<0.05)$ decreased compared with levels seen for healthy controls, but no significant effect on serum IL-6 concentration was found. The supernatant fraction of the stimulated mononuclear cells following EPA supplementation was shown to reduce the potential of isolated human hepatocytes to produce $\mathrm{C}$-reactive protein. Indeed, serum levels of C-reactive protein were found to be decreased after EPA supplementation, indicating that EPA can down regulate the acute-phase response in cancer cachexia, most likely via suppression of IL-6 production. Gogos et al. (1998) have failed to find effects of supplementation of $5 \cdot 1 \mathrm{~g} \mathrm{EPA}+\mathrm{DHA} / \mathrm{d}$ for 6 weeks on serum TNF $\alpha$, IL-6 and IL-1 levels and on ex vivo IL-1 and IL-6 production by blood mononuclear cells. However, in the malnourished subpopulation with decreased TNF $\alpha$ production, ex vivo TNF $\alpha$ production by mononuclear cells was shown to be restored to a normal level following $n-3$ PUFA supplementation. In this study survival was prolonged in the patients receiving the $n-3$ PUFA supplement. Furukawa et al. (1999) have studied the effect of an oral supplement providing $1.8 \mathrm{~g} \mathrm{EPA/d}$ to patients with oesophageal cancer post surgery who were also receiving parenteral soyabean oil. The EPA intervention was started on day 7 before surgery and was continued until postoperative day 21 . The authors have reported that serum IL6 is significantly lower $(P<0.05)$ on post-operative day 7 and lymphocyte proliferation and NK cell activity are significantly higher $(P<0 \cdot 05)$ on post-operative day 21 . Similar data have been presented by the same authors in a research letter (Takagi et al. 2001) and a symposium report (Tashiro et al. 1998), so these data are likely to derive from the same study. Finally, a very high intake of fish oil $(8 \cdot 1 \mathrm{~g} \mathrm{EPA}+\mathrm{DHA} / \mathrm{d})$ for 4 weeks has been studied in gastrointestinal cancer cachexia (Persson et al. 2005). Although fish oil supplementation was shown to result in weight stabilisation, particularly when combined with melatonin treatment, no effects on circulating TNF $\alpha$, IL$1 \beta$, IL-6 or IL-8 concentrations were observed.

Thus, these studies indicate that the production of IL-6 in these populations, either measured after ex vivo stimulation of mononuclear cells or in plasma, is decreased or not affected by EPA (and DHA) supplementation. Similar 
results have been reported in studies with EPA-enriched enteral nutrition (Barber et al. 2001). The reported increase in ex vivo TNF $\alpha$ production by mononuclear cells, lymphocyte proliferation and NK activity in some studies may reflect a (partial) immune restoration by $n-3$ PUFA supplementation.

\section{Inflammatory bowel diseases}

Ulcerative colitis and Crohn's disease are chronic inflammatory diseases of the alimentary tract. In ulcerative colitis the mucosa of the colon is mainly affected, while in Crohn's disease any part of the alimentary tract from the mouth to the anus can be affected, although it is usually the ileum and colon. In both diseases the intestinal mucosa contains elevated levels of inflammatory eicosanoids such as $\mathrm{LTB}_{4}$ (Sharon \& Stenson, 1984) and cytokines. In particular, the activation of IL-2- and IFN- $\gamma$-producing Th1 cells in the lamina propria of the Crohn's disease-affected gut plays a pivotal role in the pathogenesis (Hommes \& van Deventer, 2000).

At least twelve placebo-controlled studies using longchain $n$-3 PUFA in patients with inflammatory bowel diseases are now available and are reviewed elsewhere (Calder, 2006). Only two of these studies have reported effects on cytokine production. The earliest study (Almallah et al. 1998, 2000a,b) has reported a significant reduction $(P<0 \cdot 05)$ in serum IL-2 and soluble IL-2 receptor levels following 26 weeks of supplementation with $5.6 \mathrm{~g}$ EPA + DHA/d in patients with ulcerative colitis. This change was found to be accompanied by significant reductions $(P<0.05)$ in serum $\mathrm{LTB}_{4}$ concentration, NK cell activity and sigmoidoscopic and histological scores, and decreased disease activity. More recently, Trebble et al. (2004) have shown that $2 \cdot 7 \mathrm{~g}$ EPA+DHA/d for 24 weeks reduces the ex vivo production of IFN- $\gamma$ and $\mathrm{PGE}_{2}$, but not $\mathrm{TNF} \alpha$, by stimulated mononuclear cells from patients with Crohn's disease. These data indicate that $n-3$ PUFA may decrease disease-related inflammatory markers in inflammatory bowel diseases.

\section{Rheumatoid arthritis}

Rheumatoid arthritis is a chronic inflammatory disease characterised by joint inflammation that manifests as swelling, pain, functional impairment, morning stiffness, osteoporosis and muscle wasting. Joint lesions are characterised by infiltration of activated macrophages, $\mathrm{T}$ lymphocytes and plasma cells into the synovium (the tissue lining the joints) and by proliferation of synovial cells termed synoviocytes. Synovial biopsies from patients with rheumatoid arthritis contain high levels of TNF $\alpha$, IL- $1 \beta$, IL-6, IL-8 and granulocyte-macrophage-colony-stimulating factor, and synovial cells cultured ex vivo produce TNF $\alpha$, IL-1 $\beta$, IL-6, IL-8 and granulocyte-macrophagecolony-stimulating factor for extended periods of time without additional stimulus (Feldmann \& Maini, 1999). Cyclooxygenase-2 expression is increased in the synovium of patients with rheumatoid arthritis, and in the joint tissues in rat models of arthritis (Sano et al. 1992). $\mathrm{PGE}_{2}$,
$\mathrm{LTB}_{4}$, 5-hydroxyeicosatetraenoic acid and also plateletactivating factor are found in the synovial fluid of patients with active rheumatoid arthritis (Sperling, 1995). The efficacy of non-steroidal anti-inflammatory drugs in rheumatoid arthritis indicates the importance of pro-inflammatory cyclooxygenase pathway products in the pathophysiology of the disease. Thus, these data provide a mechanistic basis for benefits of fish oil supplementation in rheumatoid arthritis.

At least seventeen placebo-controlled studies have investigated the effect of $n-3$ PUFA in patients with rheumatoid arthritis (for review, see Calder, 2006). Five of these studies have reported effects on inflammatory cytokines (Table 4). Kremer et al. (1990) have found no effects of either $2.9 \mathrm{~g} \mathrm{EPA}+\mathrm{DHA} / \mathrm{d}$ or $5.9 \mathrm{~g} \mathrm{EPA}+\mathrm{DHA} / \mathrm{d}$ on Con A-induced IL-2 production and Con A- or PHA-induced lymphocyte proliferation. LPS-induced IL-1 production by monocytes was reported to be significantly decreased $(P<0.05)$ by $5.9 \mathrm{~g}$ EPA + DHA $/ \mathrm{d}$ but not by $2.9 \mathrm{~g}$ $\mathrm{EPA}+\mathrm{DHA} / \mathrm{d}$ in the same study. Espersen et al. (1992) and Kremer et al. (1995) have reported decreased serum IL-1 $\beta$ following $3 \cdot 2$ and $7 \cdot 1 \mathrm{~g}$ EPA + DHA/d respectively. No effect of fish oil supplementation on serum TNF $\alpha$ was found following 3·2 (Espersen et al. 1992), 3·4 (Sundrarjun et al. 2004), 4.2 (Adam et al. 2003) or 7·1 (Kremer et al. 1995) g EPA + DHA/d. However, decreased soluble TNF $\alpha$ receptor levels were found (Sundrarjun et al. 2004) after 12 weeks of supplementation with $3.4 \mathrm{~g}$ EPA + DHA/d. Serum IL-6 levels were unchanged in the same study (Sundrarjun et al. 2004) and following 7·1 g EPA+DHA/d (Kremer et al. 1995). In addition, no effects on serum IL-8 and IL-2 concentrations were found following fish oil supplementation in the latter study.

These studies indicate that fish oil may decrease IL-1 production in rheumatoid arthritis and that it has little effect on other cytokines. However, in four of these studies fish oil was found to improve clinical outcomes (Calder, 2006). Indeed, in almost all published trials of fish oil intervention in rheumatoid arthritis clinical benefits have been reported (Calder, 2006). These data therefore suggest that disease-specific clinical outcomes might be a more sensitive marker of anti-inflammatory effects of EPA + DHA than inflammatory cytokines.

\section{Lung inflammation}

COPD is characterised by reduced airflow on expiration as a result of airway obstruction. COPD is currently the fifth leading cause of death worldwide, and in the next decades its prevalence and mortality rates are expected to increase (Murray \& Lopez, 1997). COPD is characterised by chronic inflammation in the small airways and lung parenchyma accompanied by infiltration of neutrophils and macrophages (Barnes et al. 2003). This inflammation is considered to mediate excess mucous production, fibrosis and proteolysis via neutrophil recruitment. The most important neutrophil chemotactic factors implicated in COPD are IL-8, TNF $\alpha$ and $\mathrm{LTB}_{4}$ (Barnes, 2000). Airflow obstruction and a chronic persistent inflammatory process also characterise asthma, but the nature of the inflammation differs markedly from that in COPD. The 
Table 4. Effects of EPA+DHA supplementation on circulating cytokine levels, ex vivo cytokine production or lymphocyte proliferation following mitogen stimulation in intervention studies in patients with inflammatory disorders

\begin{tabular}{|c|c|c|c|c|c|c|c|c|c|}
\hline \multirow[b]{2}{*}{ Reference } & \multirow[b]{2}{*}{ Type of study } & \multirow{2}{*}{$\begin{array}{c}\text { Dose of } \\
\text { EPA+DHA }(g / d)\end{array}$} & \multirow{2}{*}{$\begin{array}{l}\text { Duration } \\
\text { (weeks) }\end{array}$} & \multicolumn{4}{|c|}{ Subjects } & \multirow[b]{2}{*}{ Markers studied } & \multirow[b]{2}{*}{ Effect seen* } \\
\hline & & & & $n$ & Gender & Age (years) & Condition & & \\
\hline \multicolumn{10}{|l|}{ Cancer } \\
\hline $\begin{array}{l}\text { Tashiro et al. (1998); } \\
\text { Furukawa et al. (1999); } \\
\text { Takagi et al. (2001) }\end{array}$ & DB, Non-PC, R & $1 \cdot 8 \mathrm{EPA}$ & 4 & 7 & $M+F$ & mean 61 & $\begin{array}{l}\text { Post surgery } \\
\text { oesophageal } \\
\text { cancer }\end{array}$ & $\begin{array}{l}\text { Serum IL-6 } \\
\text { Con A- and PHA- } \\
\text { induced LP }\end{array}$ & $\begin{array}{c}\text { IL-6 } \downarrow \text { (after } 1 \text { week) } \\
\text { Con A, } \uparrow 143 \% \text {; } \\
\text { PHA, } \uparrow 153 \%\end{array}$ \\
\hline Wigmore et al. (1997) & Open & $\begin{array}{l}\text { EPA, } 1 \mathrm{~g} w \mathrm{k} 1,2 \mathrm{~g} w \mathrm{k} \\
2,4 \mathrm{~g} w \mathrm{k} 3,6 \mathrm{~g} w \mathrm{k} 4\end{array}$ & 4 & 6 & $M+F$ & $\begin{array}{l}\text { 18-80, } \\
\text { mean } 58\end{array}$ & $\begin{array}{l}\text { Pancreatic cancer } \\
\text { cachexia }\end{array}$ & $\begin{array}{l}\text { Serum IL-6 } \\
\text { LPS-induced IL-6 }\end{array}$ & $\begin{array}{l}\text { None } \\
\text { IL-6, } \downarrow 65 \%\end{array}$ \\
\hline Gogos et al. (1998) & $\mathrm{PC}, \mathrm{R}$ & $5 \cdot 1(3 \cdot 1+2 \cdot 1)$ & 6 & 30 & $M+F$ & mean 57 & $\begin{array}{l}\text { Cancer, half of } \\
\text { patients } \\
\text { malnourished }\end{array}$ & $\begin{array}{l}\text { Serum TNF } \alpha \text {, IL-6, IL-1 } \\
\text { LPS-induced TNF } \alpha \text {, } \\
\text { IL-6, IL-1 }\end{array}$ & $\begin{array}{l}\text { None } \\
\text { TNF } \alpha, \uparrow \text { malnourished; } \\
\text { IL-6, IL-1, none }\end{array}$ \\
\hline Persson et al. (2005) & $\begin{array}{l}\text { Open, } \\
\text { non-PC, R }\end{array}$ & $8 \cdot 1(4 \cdot 9+3 \cdot 2)$ & 4 & 13 & $M+F$ & $\begin{array}{l}52-78, \\
\text { mean } 66\end{array}$ & $\begin{array}{l}\text { Gastrointestinal } \\
\text { cancer cachexia }\end{array}$ & $\begin{array}{l}\text { Serum TNF } \alpha, \text { IL-1 } \beta \text {, } \\
\text { sIL-2R, IL-6, IL-8 }\end{array}$ & None \\
\hline \multicolumn{10}{|c|}{ Inflammatory bowel diseases } \\
\hline Trebble et al. (2004) & $\mathrm{DB}, \mathrm{PC}, \mathrm{R}$ & $2 \cdot 7(1 \cdot 6+1 \cdot 1)$ & 24 & 31 & $M+F$ & mean 45 & $\begin{array}{l}\text { Crohn's disease, } \\
\text { IFN- } \gamma \text { increased } \\
\text { in pathology }\end{array}$ & $\begin{array}{l}\text { Con A-induced IFN- } \gamma \\
\text { LPS-induced TNF } \alpha\end{array}$ & $\begin{array}{l}\downarrow 50 \% \\
\text { None }\end{array}$ \\
\hline Almallah et al. (2000a) & $\mathrm{PC}, \mathrm{R}$ & $5 \cdot 6(3 \cdot 2+2 \cdot 4)$ & 26 & 9 & $M+F$ & & Procto-colitis & Serum IL-2, IL-2R & IL-2, $\downarrow ;$ IL-2R, $\downarrow$ \\
\hline \multicolumn{10}{|l|}{ Rheumatoid arthritis (RA) } \\
\hline Kremer et al. (1990) & $\begin{array}{l}\mathrm{DB}, \mathrm{PC}, \mathrm{R} \\
\text { parallel }\end{array}$ & $2 \cdot 9(1 \cdot 7+1 \cdot 2)$ & 24 & 20 & $M+F$ & $\begin{array}{l}\text { 32-81, } \\
\quad \text { mean } 59\end{array}$ & RA & $\begin{array}{l}\text { LPS-induced IL-1 } \\
\text { Con A-induced IL-2 } \\
\text { Con A- and PHA- } \\
\text { induced LP }\end{array}$ & $\begin{array}{l}\text { None } \\
\text { None } \\
\text { None }\end{array}$ \\
\hline Espersen et al. (1992) & $\mathrm{DB}, \mathrm{PC}, \mathrm{R}$ & $3 \cdot 2(2 \cdot 0+1 \cdot 2)$ & 12 & 18 & $M+F$ & & RA & Serum IL-1 $\beta$, TNF $\alpha$ & IL-1 $\beta, \downarrow ;$ TNF $\alpha$, none \\
\hline Sundrarjun et al. (2004) & $\mathrm{PC}, \mathrm{R}$ & $3 \cdot 4(1 \cdot 9+1 \cdot 5)$ & 12 & 23 & $M+F$ & mean 46 & RA & $\begin{array}{l}\text { Serum IL-6, TNF } \alpha \text {, } \\
\text { sTNFR }\end{array}$ & $\begin{array}{l}\text { IL-6, TNF } \alpha, \\
\text { none; sTNFR } \downarrow\end{array}$ \\
\hline Adam et al. (2003) & $P C, R$ & $4 \cdot 2(2 \cdot 4+1 \cdot 8)$ & 12 & 30 & $M+F$ & mean 58 & RA & Serum IL-1 $\beta$, TNF $\alpha$ & None \\
\hline Kremer et al. (1990) & $\begin{array}{l}\mathrm{DB}, \mathrm{PC}, \mathrm{R}, \\
\text { parallel }\end{array}$ & $5.9(3.5+2.4)$ & 24 & 17 & $M+F$ & $\begin{array}{l}30-80 \\
\text { mean } 58\end{array}$ & RA & $\begin{array}{l}\text { LPS-induced IL-1 } \\
\text { Con A-induced IL-2 } \\
\text { Con A- and PHA- } \\
\text { induced LP }\end{array}$ & $\begin{array}{l}\downarrow 55 \% \\
\text { None } \\
\text { None }\end{array}$ \\
\hline Kremer et al. (1995) & $\mathrm{DB}, \mathrm{PC}$ & $7 \cdot 1(4 \cdot 6+2 \cdot 5)$ & 26 to 30 & 23 & $M+F$ & mean 58 & RA & $\begin{array}{l}\text { Serum IL-1 } \beta, \text { IL-6, } \\
\text { TNF } \alpha, \text { IL-8, IL-2 }\end{array}$ & $\begin{array}{l}\text { IL-1 } \beta, \downarrow \text {; IL-6, TNF } \alpha \text {, } \\
\text { IL-8, IL-2, none }\end{array}$ \\
\hline \multicolumn{10}{|l|}{ Lung inflammation } \\
\hline Matsuyama et al. (2005) & $\mathrm{DB}, \mathrm{PC}, \mathrm{R}$ & 0.6 & 104 & 32 & $M+F$ & mean 66 & COPD & Sputum IL-8, TNF $\alpha$ & $\begin{array}{l}\text { IL-8, } \downarrow 55 \% ; \\
\text { TNF } \alpha, \downarrow 48 \% \\
\text { None }\end{array}$ \\
\hline Broekhuizen et al. (2005) & $\mathrm{DB}, \mathrm{PC}, \mathrm{R}$ & $\begin{array}{c}1 \cdot 0(0.7+0.3)+0.7 \\
\text { GLA }+1 \cdot 2 \\
\text { ALA }+0.4 \text { STA }\end{array}$ & 8 & 51 & $M+F$ & mean 64 & COPD & $\begin{array}{l}\text { Serum IL-8 TNF } \alpha \\
\text { Serum IL-6, TNF } \alpha\end{array}$ & $\begin{array}{l}\text { None } \\
\text { None }\end{array}$ \\
\hline $\begin{array}{l}\text { Mickleborough } \\
\text { et al. (2006) }\end{array}$ & $\mathrm{DB}, \mathrm{PC}, \mathrm{R}$ & $5 \cdot 2(3 \cdot 2+2 \cdot 0)$ & 3 & 8 & $M+F$ & mean 23 & $\begin{array}{l}\text { Exercise-induced } \\
\text { broncho-constriction } \\
\text { in asthma }\end{array}$ & Sputum IL-1 $\beta$, TNF $\alpha$ & IL-1 $\beta, \downarrow ;$ TNF $\alpha, \downarrow$ \\
\hline
\end{tabular}




6

$9 \mathrm{M}$

30-52, HIV
mean 36

Bell et al. (1996)

$\mathrm{DB}, \mathrm{PC}, \mathrm{R}$

$2(1 \cdot 0+1 \cdot 0)$

Hellerstein et al. (1996)

Open

$4 \cdot 5(2 \cdot 7+1 \cdot 8)$

\section{6}

$10 \mathrm{M}$

30-43,

mean 38

mean 41

HIV

$16 \mathrm{M}$

HIV wasting

\section{Obesity}

Jellema et al. (2004)

Chan et al. (2002)

DB, PC, $R$

$1 \cdot 1(0 \cdot 6+0 \cdot 5)$

\section{6}

$11 \mathrm{M}$

mean 59

$12 \mathrm{M}$ mean 54
BMI $30-35 \mathrm{~kg} / \mathrm{m}^{2}$
Central obesity,$$
\text { BMI }>29 \mathrm{~kg} / \mathrm{m}^{2}
$$

\section{Diabetes}

Molvig et al. (1991)

Open

$3 \cdot 2(2+1 \cdot 2)$

Mori et al. (2003)

DB, PC, R,

3.7 DHA

Mori et al. (2003)

DB, P,C R,

3.8 EPA

Other inflammatory conditions

Gallai et al. (1995)

Open

$5 \cdot 2(3 \cdot 1+2 \cdot 1)$

$8 \mathrm{M}$

mean 24

Type 1 diabetes

6

$18 \mathrm{M}+\mathrm{F}$

40-75,

mean 61

6

$17 \mathrm{M}+\mathrm{F}$ 40-75,

mean 61

Type 2 diabetes

Type 2 diabetes

$15 \mathrm{M}+\mathrm{F} \quad 20-50$

Multiple sclerosis

Soyland et al. (1994)

$\mathrm{DB}, \mathrm{PC}, \mathrm{R}$

$5 \cdot 0(3 \cdot 1+1 \cdot 9)$

16

$21 M+F$

Cappelli et al. (1997)

Open non-PC $\quad 2.9$

52
LPS-induced IL-1 $\beta$

IL-1 $\beta, \downarrow 33 \%$

LPS-induced TNF $\alpha$, IL-6 $\quad$ IL- $6 \uparrow$, TNF $\alpha$, none

Serum TNF $\alpha$, IL-1 $\beta$, IFN- $\alpha$ None LPS- and PHA-induced None TNF $\alpha$, IL-1 $\beta$

Serum sTNF $\alpha R$, None

IL-6, TNF $\alpha$

Serum TNF $\alpha$, IL-6 None

PHA-induced LP $\quad \downarrow 50 \%$

LPS-induced TNF $\alpha$, IL-1 $\beta$ None

Serum TNF $\alpha$, IL-6 None

Serum TNF $\alpha$, IL-6 None

Serum SIL-2R $\quad \downarrow 30 \%$

PHA-induced IL-2 $\quad \downarrow 25 \%$

Con A-induced IFN- $\gamma \quad \downarrow 45 \%$

LPS-induced TNF $\alpha$, IL-1 $\beta \quad$ IL-1 $\beta, \downarrow 24 \%$;

TNF $\alpha, \downarrow 25 \%$

PHA-induced LP, IL-2, None

IL-6, TNF $\alpha$

PHA-induced IL-2, $\quad \quad$ TNF $\alpha \downarrow 34 \%$, IL-1 $\beta$, TNF $\alpha \quad$ IL-2, IL-1 $\beta$ : None 
inflammation in asthma is predominantly eosinophilic and the most important cytokines involved are IL-4, IL-5 and IL-13 (Barnes, 2000). Control of inflammatory mediators is an important aspect in the treatment strategy of both inflammatory lung diseases.

Two recent studies (Broekhuizen et al. 2005; Matsuyama et al. 2005) have investigated the effects of relatively-low supplemental intake of $\mathrm{EPA}+\mathrm{DHA}$ on inflammatory markers, as well as exercise capacity, in COPD. Broekhuizen et al. (2005) have reported improved exercise capacity in a cycling test but no effect on systemic levels of IL- 6 and TNF $\alpha$ following intake of a supplement containing $1.0 \mathrm{~g} \mathrm{EPA}+\mathrm{DHA} / \mathrm{d}$. Matsuyama et al. (2005) have measured both systemic (serum) and sputum TNF $\alpha$ and IL-8 levels in a 2-year intervention with a supplemental intake of $0.6 \mathrm{~g} \mathrm{EPA}+\mathrm{DHA} / \mathrm{d}$. Notably, although no differences in serum cytokine concentrations were found in this study, decreased sputum TNF $\alpha$ and IL-8 levels were observed in the group receiving $n-3$ PUFA, accompanied by improved exercise capacity in a walk test. The only comparable study of asthma has reported the effects of a high level of fish oil $(5 \cdot 2 \mathrm{~g} \mathrm{EPA}+\mathrm{DHA} / \mathrm{d})$ on sputum inflammatory cytokines and pulmonary function in exercise-induced broncho-constriction (Mickleborough et al. 2006). Concentrations of TNF $\alpha$ and IL-1 $\beta$ in the sputum supernatant fraction were found to be significantly lower $(P<0.05)$ in the fish oil group and this change was accompanied by improved pulmonary function.

In conclusion, these studies indicate that EPA+DHA supplementation in inflammatory lung diseases results in a local rather than a systemic decrease in inflammatory cytokines, even at relatively low intake levels. As these local effects are associated with improved clinical outcomes, cytokine concentrations in inflamed tissue might be a more sensitive marker and predictor of anti-inflammatory efficacy of EPA+DHA supplementation than systemic cytokines.

\section{HIV infection and AIDS}

Generally, HIV infection and disease progression is not considered to be predominantly an inflammatory disease. Gradual depletion of T lymphocytes is considered to be the most distinct and important immunological feature of HIV disease progression. However, there is substantial evidence to indicate that HIV disease progression is also associated with persistent presence of (subclinical) inflammation, particularly in the intestinal mucosa. It is uncertain whether a mucosal inflammatory response in the intestine is a result of either HIV infection or altered enterocyte function and activity. It is clear, however, that during the progression of the disease there are distinct kinetics of production of local pro-inflammatory cytokines (McGowan et al. 1994, 2004; Reka et al. 1994; Sharpstone et al. 1996). There is elevation of TNF $\alpha$, IL-1 $\beta$ and IL-6 in particular and to a lesser extent IFN- $\gamma$ in intestinal biopsies from patients infected with HIV. The kinetics of the production of these cytokines and the increased local tissue levels strongly depend on the stage of disease, i.e. TNF $\alpha$ and IL- $1 \beta$ increase during the progression of disease. It has been shown in models of intestinal barrier function that pro-inflammatory cytokines can have strong detrimental effects on intestinal barrier disruption by increasing paracellular permeability (McKay \& Baird, 1999; Nusrat et al. 2000). Disruption of intestinal barrier integrity, as determined by increased epithelial permeability, has also been reported in patients infected with HIV. This barrier disruption seems to worsen during the course of disease (Lima et al. 1997). It has therefore been hypothesised that the underlying mechanism most likely involves pro-inflammatory cytokines such as TNFo, IFN- $\gamma$ and IL-1 $\beta$ (Stockmann et al. 1998, 2000; Schmitz et al. 2002). A more-widely-acknowledged aspect of the proinflammatory response during HIV infection is the AIDSrelated wasting syndrome. It has been estimated that in the USA $35 \%$ of patients with AIDS are cachectic (Morley et al. 2006). Elaboration of pro-inflammatory cytokines is probably the major factor responsible for AIDS wasting (Morley et al. 2006). Studies investigating the effects of fish oil supplementation on cytokine concentrations and responses in patients who were HIV positive were conducted against the background of potential benefits on lean body mass.

Three relatively-small studies ( $n$ 9-16; Bell et al. 1996; Hellerstein et al. 1996; Virgili et al. 1997) have investigated the effects of fish oil supplementation on cytokine concentrations and responses in patients who were HIV positive. Virgili et al. (1997) have reported decreased LPSinduced IL-1 $\beta$ production following $1.8 \mathrm{~g} \mathrm{EPA}+\mathrm{DHA} / \mathrm{d}$ for 6 weeks. On the other hand, Bell et al. (1996) have reported increased LPS-induced IL- 6 production and no effect on TNF $\alpha$ production after $2 \cdot 0 \mathrm{~g}$ EPA + DHA/d for 6 weeks. Finally, Hellerstein et al. (1996) have reported no effects of $4.5 \mathrm{~g}$ EPA + DHA/d on serum TNF $\alpha$, IL- $1 \beta$ and IFN- $\gamma$ concentrations, LPS- and PHA-induced production of TNF $\alpha$ and IL-1 $\beta$ or weight loss in a study of patients with AIDS-associated weight loss. None of these studies have reported significant effects of $n-3$ PUFA on T-cell counts.

In conclusion, as a fish oil-rich supplement has no adverse effect on T-cell counts in these or other studies of individuals infected with HIV or positive for AIDS (Pichard et al. 1998; de Luis Roman et al. 2001; Keithley et al. 2002), this intervention appears to be safe in HIV infection and AIDS. Although there appears to be no consistent effect of fish oil supplementation on systemic cytokine production in patients infected with HIV or positive for AIDS, to date there are no data available on the effect of EPA +DHA enrichment on local markers of inflammation in the intestinal mucosa. It would therefore be useful to investigate the effects of EPA+DHA on mucosal inflammation and intestinal barrier integrity in patients infected with HIV, as such an approach might be more likely to reveal potential clinically-relevant benefits of EPA+DHA supplementation to these patients.

\section{Obesity}

Obese individuals are at increased risk for a range of metabolic diseases, including insulin resistance, dyslipidaemia and hypertension. Adipose tissue is an important endocrine organ, secreting a range of inflammatory mediators, including TNF $\alpha$ and IL-6. Circulating concentrations of these cytokines are increased in obesity and may contribute 
to the pathogenesis of metabolic diseases (Browning, 2003). Hence, obesity is considered as a low-grade chronic inflammatory state.

Two studies (Chan et al. 2002; Jellema et al. 2004) have investigated the effects of supplementation with fish oil (providing either 1.1 (Jellema et al. 2004) or 3.4 (Chan et al. 2002) g EPA + DHA/d) for 6 weeks on serum $\mathrm{TNF} \alpha$ and IL-6 concentrations in obese men. Fish oil supplementation was not found to significantly affect the concentrations of circulating cytokines in either study. Hence, these studies do not provide evidence that EPA $+\mathrm{DHA}$ supplementation has favourable effects on markers for the low-grade inflammatory state in obesity.

\section{Diabetes}

Inflammatory cytokines have been implicated in the inflammatory processes leading to the destruction of the Islets of Langerhans in type 1 diabetes (Mandrup-Poulsen et al. 1989). In addition, prospective epidemiological studies have found that patients with type 2 diabetes have increased levels of inflammatory markers such as ARAderived F2-isoprostanes (Gopaul et al. 1995), IL-6 (Pradhan et al. 2001), TNFo (Nilsson et al. 1998) and C-reactive protein (Pradhan et al. 2001). It has been suggested that elevated levels of these markers are associated with increased oxidative stress in patients with type 2 diabetes (Mori et al. 2003). Hence, both insulin-dependent and non-insulin-dependent diabetes are considered to be disorders with an inflammatory component.

Molvig et al. (1991) have studied the effects of $3 \cdot 2 \mathrm{~g}$ $\mathrm{EPA}+\mathrm{DHA} / \mathrm{d}$ in a small cohort of men with type 1 diabetes parallel to an age-matched cohort of healthy men. As in the healthy subjects, no effect on LPS-induced TNF $\alpha$ and IL-1 $\beta$ production was found but PHA-induced lymphocyte proliferation was found to be decreased by $50 \%$ in the patients with diabetes. Mori et al. (2003) have studied the effects of a supplemental intake of either $3.8 \mathrm{~g}$ purified EPA/d or $3.7 \mathrm{~g}$ purified DHA/d on serum IL-6 and TNF $\alpha$ concentrations in patients with type 2 diabetes who were hypertensive. Although no statistically significant effects on serum IL-6 and TNF $\alpha$ were found, TNF $\alpha$ concentrations tended to be lower after 6 weeks of treatment with either EPA or DHA compared with baseline levels. Postintervention TNF $\alpha$ concentrations were $20 \%$ lower in the group receiving EPA and $33 \%$ lower in the group receiving DHA.

\section{Other inflammatory conditions}

In addition to the inflammatory disorders addressed previously, the effects of EPA + DHA on the selected immune markers in psoriasis, chronic renal disease and multiple sclerosis have been investigated in only one study for each of these disorders. Soyland et al. (1994) have found no effects on PHA-induced lymphocyte proliferation or IL-2, IL-6 and TNF $\alpha$ production following treatment with $5 \cdot 0 \mathrm{~g}$ $\mathrm{EPA}+\mathrm{DHA} / \mathrm{d}$ for 16 weeks in patients with psoriasis. Cappelli et al. (1997) have reported decreased PHAinduced TNF $\alpha$ production but no effects on PHA-induced IL-1 $\beta$ and IL-2 production in patients with chronic progressive renal disease following treatment with $2.9 \mathrm{~g}$ $\mathrm{EPA}+\mathrm{DHA} / \mathrm{d}$ for 1 year. Gallai et al. (1995) have studied the effects of $5 \cdot 2 \mathrm{~g} \mathrm{EPA}+\mathrm{DHA} / \mathrm{d}$ for 26 weeks in healthy subjects (for details, see Tables 2 and 3 ) and patients with multiple sclerosis and have reported decreased PHAinduced IL-2 production, decreased Con A-induced IFN- $\gamma$ production and decreased LPS-induced TNF $\alpha$ and IL-1 $\beta$ production in the patients with multiple sclerosis. These effects were similar to those for the healthy subjects in this study.

\section{Discussion and conclusions}

Dietary supplementation with long-chain $n$-3 PUFA from fish oil (EPA and DHA) increases the proportion of these fatty acids in immune cells and changes the production of important mediators and regulators of inflammation and immune responses, such as PG, LT and resolvins, towards a more anti-inflammatory profile. The incorporation of EPA and DHA into human inflammatory cells (Healy et al. 2000) and the decreased production of pro-inflammatory $\mathrm{PGE}_{2}$ occur in a dose-dependent fashion (Rees et al. 2006). Furthermore, an inverse relationship between mononuclear cell EPA content and the production of TNF $\alpha$ and IL-1 $\beta$ by these cells has been reported (Caughey et al. 1996). These observations suggest that the effects of EPA and DHA on inflammation and markers of immune function might be dose-dependent. The study by Rees et al. (2006) suggests that the threshold value of such an effect may be between $1.65 \mathrm{~g} \mathrm{EPA}+\mathrm{DHA} / \mathrm{d}$ and $3.3 \mathrm{~g} \mathrm{EPA}+\mathrm{DHA} / \mathrm{d}$, at least in healthy volunteers, as decreased $\mathrm{PGE}_{2}$ production was found at $3.3 \mathrm{~g} / \mathrm{d}$, with a larger decrease at $4.95 \mathrm{~g} / \mathrm{d}$, but no significant effect at $1 \cdot 65 \mathrm{~g} / \mathrm{d}$.

Overall, the current data from supplementation studies in healthy subjects fail to reveal a threshold value for, and dose-response effects on, immunomodulation with $\mathrm{EPA}+\mathrm{DHA}$. First, there is no clear trend that intervention cohorts with decreased inflammatory cytokine and lymphocyte proliferation responses are found more often in the upper range of intake. Second, there are no clear indications that the percentage decrease in cytokine production and lymphocyte proliferation following EPA+DHA supplementation is higher in the higher dose range. Third, most studies in healthy subjects, particularly those with the best-quality design (double-blind, placebo-controlled, randomised and parallel), have not found effects of EPA and DHA on cytokine production and lymphocyte proliferation. The latter observation particularly indicates that healthy subjects are relatively insensitive to modulation of the cell and cytokine response with long-chain $n-3$ PUFA, even at intake levels that raise EPA concentration in mononuclear cell phospholipids from approximately $0.6 \%$ total fatty acids to $4 \cdot 1 \%$ total fatty acids (Rees et al. 2006). Rees et al. (2006) have observed that older subjects incorporate EPA more readily than younger subjects, and that older subjects are more sensitive to the immunological effects of EPA. This observation is consistent with differences in lymphocyte proliferation responsiveness between older and young subjects (see p. 240). In addition, based on direct comparison of young and older subjects 
there is some evidence to suggest that older women are more sensitive to the ability of long-chain $n-3$ PUFA to decrease production of inflammatory cytokines (Meydani et al. 1991), but this finding is not confirmed in a study comparing young and older males (Rees et al. 2006), and there is no evidence to suggest that older subjects are more sensitive to modulation of $\mathrm{T}$-cell cytokine responses than younger subjects. Taken together, there is no conclusive evidence that the immunomodulatory effects of EPA+ DHA in healthy subjects are dose dependent, which may be related to the apparent low sensitivity of healthy subjects to such modulation.

The data summarised in Table 4 show that inflammatory cytokine concentrations or production are influenced by fish oil in a relatively large number of studies conducted in patients with inflammatory conditions. This observation suggests that patients with an inflammatory condition might be more sensitive to the immunomodulatory effects of long-chain $n-3$ PUFA than healthy subjects. This difference could potentially be related to depletion of the buffering capacity present in healthy subjects, e.g. as a result of a higher turnover rate of immune cells in disease and of the fatty acids in immune cell phospholipids for use as substrate for eicosanoid synthesis or as ligands for transcription factors. In addition, some studies, particularly those in patients with COPD, indicate that local effects at the site of inflammation might be more pronounced than systemic effects (for references, see Table 4). In addition, the Trebble et al. (2004) study of Crohn's disease indicates that disease-related T-cell markers might be more sensitive to immunomodulation by fish oil than the same T-cell markers in healthy subjects. The presence of inflamed tissue or 'sensitised' immune cells in inflammatory disorders and the absence of these factors in healthy subjects might (partially) explain the differential immunomodulation seen. As the designs and experimental conditions used differ between studies it is not possible to thoroughly investigate the potential presence of dose-response effects. The limited data that allow direct comparison within the same inflammatory disorder provide no clear indication of a dose-response effect of EPA + DHA supplementation on immune markers. Importantly, in a substantial number of these studies clinical benefits related to the inflammatory state of the condition were observed in the absence of significant effects on immune markers of inflammation. This observation indicates that EPA + DHA might exert anti-inflammatory effects without revealing these effects if only certain immune markers are considered. This possibility implies that condition-specific clinical end points such as joint tenderness and morning stiffness in rheumatoid arthritis or exercise performance in COPD might be more sensitive markers of modulation by EPA + DHA than cytokines. Taken together, the observations indicate that studies in healthy subjects are a useful tool to describe the general principles of immunomodulation by $n-3$ PUFA, as in general the direction of immunomodulation in healthy subjects (if any) and in inflammatory conditions is the same. However, the extent of the effect might be very different in inflammatory conditions, indicating that studies in healthy subjects are not very appropriate for establishing dose levels for specific applications in inflammatory con- ditions. In some specific situations, such as in immune suppression induced by malnourishment (Gogos et al. 1998) or surgery (stress; Furukawa et al. 1999) in patients with cancer the direction of the modulation might be opposite to that seen in healthy subjects and in patients with a chronic inflammatory disorder. Also, it is possible that in such conditions EPA + DHA contribute to a normalisation of the immune response.

Traditionally, EPA rather than DHA has been considered as the most important and potent immunomodulatory $n-3$ PUFA, as its mechanistic basis of being an alternative substrate for eicosanoid synthesis is well described. More recently, DHA-derived mediators D-series resolvins, docosatrienes and neuroprotectins, also produced by cyclooxygenase- 2 and lipoxygenase under some conditions, have been identified that also appear to be antiinflammatory and inflammation resolving (Hong et al. 2003; Marcheselli et al. 2003; Mukherjee et al. 2004). Only two studies in the current overview provide direct comparison of the effects of EPA and DHA. The first study (Kew et al. 2004) has shown that a similarly high intake of either EPA or DHA has no effect on cytokine production but that only DHA reduces CD69 expression, a marker of T-cell activation, in healthy subjects. The second study (Mori et al. 2003) has shown that serum TNF $\alpha$ concentrations are at least equally affected by DHA intake compared with EPA intake in subjects with type 2 diabetes. Conclusive evidence of the relative contribution of EPA and DHA is still lacking but these observations, together with the mechanistic understanding of DHA-based effects that is now available, may change the traditional view of the relative contributions of EPA and DHA.

The importance of the dampening effect of EPA + DHA on some markers of immune function in relation to the immune response in general and disease resistance is not well described. The observations in some studies that $\mathrm{EPA}+\mathrm{DHA}$ decrease cytokine and lymphocyte proliferation responses may lead to the conclusion that EPA+ DHA are immunosuppressive and therefore disadvantageous to the host's immune function and disease resistance. However, there are no data to suggest that either supplementation with fish oil or high background intakes of EPA+DHA (e.g. in the Japanese, Greenland Inuit, Norwegian or Icelandic populations) increase susceptibility to infectious diseases. The immunomodulatory effects observed in some studies with healthy subjects might equally well reflect a correction towards normalised, less exaggerated, responses, indicating a more balanced and effective immune response. The later hypothesis is supported by a few observations. The findings of a large study on the risk of community-acquired pneumonia and fatty acid intake (Merchant et al. 2005) indicate that pneumonia risk is reduced by $31 \%$ for every $1 \mathrm{~g} / \mathrm{d}$ increase in intake of $\alpha$-linolenic acid $(18: 3 n-3)$ and by $4 \%$ for every $1 \mathrm{~g} / \mathrm{d}$ increase in linoleic acid intake. In this study linoleic and $\alpha$-linolenic acids were derived from common food sources, so their effects could not be separated. $\alpha$-Linolenic acid has a much larger effect than linoleic acid and increased $\alpha$ linolenic acid intake increases EPA levels in immune cells (Burdge \& Calder, 2005). Thus, increased EPA levels in immune cells might explain this observation. Moreover, 
among subjects with low $n-6$ and $n-3$ fatty acid intakes from plant sources, high fish intake is associated with reduced pneumonia risk (Merchant et al. 2005). Second, observations associated with an epidemic of measles in Greenland in 1951, triggered by an infected Danish sailor, support this view. The epidemic in this naïve population shows the same characteristics (e.g. expected numbers of cases, complications) as previous epidemics recorded in other naïve populations elsewhere in the world (Kronborg et al. 1992). As this naïve Inuit population in Greenland traditionally consume a long-chain $n-3$ PUFA-rich diet, these observations suggests that these fatty acids do not worsen the response to the virus (Calder, 2001b). Third, evidence from clinical trials of patients with trauma and cancer who were hospitalised (Heyland et al. 2001) suggests that EPA+DHA-enriched 'immunonutrition' may decrease, not increase, infectious complication rates. However, because of the combination of nutrients such as arginine, nucleotides and long-chain $n-3$ PUFA in the enteral formulas used in these studies, it is not possible to discern how much of the reported effects are attributable to $n$-3 PUFA. Thus, these limited data support the view that high EPA+DHA consumption does not impair immune function and may be beneficial for infectious disease resistance. For conclusive statements on this issue, wellpowered supplementation studies designed to identify effects of EPA + DHA on infection rates are required.

In conclusion, the current review provides no evidence for strong dose-dependent immunomodulatory effects of EPA + DHA in healthy subjects. The apparent absence of dose-dependent effects might be a result of the relative insensitivity of healthy subjects to such modulation. The presence of an inflammatory condition might increase the sensitivity to the immunomodulatory effects of $\mathrm{EPA}+\mathrm{DHA}$. In addition, there is substantial evidence to suggest that some condition-specific clinical end points are more sensitive markers to these effects than immune markers. Studies in healthy subject are a useful tool for investigating the general principles of EPA + DHA modulation, rather than for determining the dose required in specific inflammatory conditions. The concern that the potential immunosuppressive effects of EPA + DHA might impair immune function or infectious disease resistance is not supported by the studies considered here. Indeed, in some conditions the immunomodulatory effects of $\mathrm{EPA}+\mathrm{DHA}$ might improve immune function and disease resistance.

\section{References}

Abbate R, Gori AM, Martini F, Brunelli T, Filippini M, Francalanci I, Paniccia R, Prisco D, Gensini GF \& Neri Serneri GG (1996) n-3 PUFA supplementation, monocyte PCA expression and interleukin-6 production. Prostaglandins, Leukotrienes, and Essential Fatty Acids 54, 439-444.

Adam O, Beringer C, Kless T, Lemmen C, Adam A, Wiseman M, Adam P, Klimmek R \& Forth W (2003) Anti-inflammatory effects of a low arachidonic acid diet and fish oil in patients with rheumatoid arthritis. Rheumatology International $\mathbf{2 3}$, 27-36.
Albers R, Antoine JM, Bourdet-Sicard R, Calder PC, Gleeson M, Lesourd B, Samartin S, Sanderson IR, Van Loo J, Vas Dias FW \& Watzl B (2005) Markers to measure immunomodulation in human nutrition intervention studies. British Journal of Nutrition 94, 452-481.

Almallah YZ, El-Tahir A, Heys SD, Richardson S \& Eremin O (2000a) Distal procto-colitis and n-3 polyunsaturated fatty acids: the mechanism(s) of natural cytotoxicity inhibition. European Journal of Clinical Investigation 30, 58-65.

Almallah YZ, Ewen SW, El-Tahir A, Mowat NA, Brunt PW, Sinclair TS, Heys SD \& Eremin O (2000b) Distal proctocolitis and $n-3$ polyunsaturated fatty acids (n-3 PUFAs): the mucosal effect in situ. Journal of Clinical Immunology 20, 68-76.

Almallah YZ, Richardson S, O'Hanrahan T, Mowat NA, Brunt PW, Sinclair TS, Ewen S, Heys SD \& Eremin O (1998) Distal procto-colitis, natural cytotoxicity, and essential fatty acids. American Journal of Gastroenterology 93, 804-809.

Bach JF (2002) The effect of infections on susceptibility to autoimmune and allergic diseases. New England Journal of Medicine 347, 911-920.

Bagga D, Wang L, Farias-Eisner R, Glaspy JA \& Reddy ST (2003) Differential effects of prostaglandin derived from omega- 6 and omega-3 polyunsaturated fatty acids on COX-2 expression and IL-6 secretion. Proceedings of the National Academy of Sciences USA 100, 1751-1756.

Barber MD, Fearon KC, Tisdale MJ, McMillan DC \& Ross JA (2001) Effect of a fish oil-enriched nutritional supplement on metabolic mediators in patients with pancreatic cancer cachexia. Nutrition and Cancer 40, 118-124.

Barnes PJ (2000) Mechanisms in COPD: differences from asthma. Chest 117, 10S-14S.

Barnes PJ, Shapiro SD \& Pauwels RA (2003) Chronic obstructive pulmonary disease: molecular and cellular mechanisms. European Respiratory Journal 22, 672-688.

Bechoua S, Dubois M, Vericel E, Chapuy P, Lagarde M \& Prigent AF (2003) Influence of very low dietary intake of marine oil on some functional aspects of immune cells in healthy elderly people. British Journal of Nutrition 89, 523-531.

Bell SJ, Chavali S, Bistrian BR, Connolly CA, Utsunomiya T \& Forse RA (1996) Dietary fish oil and cytokine and eicosanoid production during human immunodeficiency virus infection. Journal of Parenteral and Enteral Nutrition 20, 43-49.

Blok WL, Deslypere JP, Demacker PN, van der Ven-Jongekrijg J, Hectors MP, van der Meer JW \& Katan MB (1997) Pro- and anti-inflammatory cytokines in healthy volunteers fed various doses of fish oil for 1 year. European Journal of Clinical Investigation 27, 1003-1008.

Broekhuizen R, Wouters EF, Creutzberg EC, Weling-Scheepers CA \& Schols AM (2005) Polyunsaturated fatty acids improve exercise capacity in chronic obstructive pulmonary disease. Thorax 60, 376-382.

Browning LM (2003) n-3 Polyunsaturated fatty acids, inflammation and obesity-related disease. Proceedings of the Nutrition Society 62, 447-453.

Burdge GC \& Calder PC (2005) Conversion of alpha-linolenic acid to longer-chain polyunsaturated fatty acids in human adults. Reproduction, Nutrition, Development 45, 581-597.

Calder PC (2001a) N-3 polyunsaturated fatty acids, inflammation and immunity: pouring oil on troubled waters or another fishy tale? Nutrition Research 21, 309-341.

Calder PC (2001b) Polyunsaturated fatty acids, inflammation, and immunity. Lipids 36, 1007-1024.

Calder PC (2003) N-3 polyunsaturated fatty acids and inflammation: from molecular biology to the clinic. Lipids 38, 343-352.

Calder PC (2006) n-3 Polyunsaturated fatty acids, inflammation, and inflammatory diseases. American Journal of Clinical Nutrition 83, S1505-S1519. 
Calder PC, Yaqoob P, Thies F, Wallace FA \& Miles EA (2002) Fatty acids and lymphocyte functions. British Journal of Nutrition 87, S31-S48.

Cannon JG, Fiatarone MA, Meydani M, Gong J, Scott L, Blumberg JB \& Evans WJ (1995) Aging and dietary modulation of elastase and interleukin-1 beta secretion. American Journal of Physiology 268, R208-R213.

Cappelli P, Di Liberato L, Stuard S, Ballone E \& Albertazzi A (1997) N-3 polyunsaturated fatty acid supplementation in chronic progressive renal disease. Journal of Nephrology $\mathbf{1 0}$, 157-162.

Caughey GE, Mantzioris E, Gibson RA, Cleland LG \& James MJ (1996) The effect on human tumor necrosis factor alpha and interleukin 1 beta production of diets enriched in n-3 fatty acids from vegetable oil or fish oil. American Journal of Clinical Nutrition 63, 116-122.

Chan DC, Watts GF, Barrett PHR, Beilin LJ \& Mori TA (2002) Effect of atorvastatin and fish oil on plasma high-sensitivity Creactive protein concentrations in individuals with visceral obesity. Clinical Chemistry 48, 877-883.

Ciubotaru I, Lee YS \& Wander RC (2003) Dietary fish oil decreases C-reactive protein, interleukin-6, and triacylglycerol to HDL-cholesterol ratio in postmenopausal women on HRT. Journal of Nutritional Biochemistry 14, 513-521.

Cooper AL, Gibbons L, Horan MA, Little RA \& Rothwell NJ (1993) Effect of dietary fish oil supplementation on fever and cytokine production in human volunteers. Clinical Nutrition 12, 321-328.

Daviglus ML, Stamler J, Orencia AJ, Dyer AR, Liu K, Greenland P, Walsh MK, Morris D \& Shekelle RB (1997) Fish consumption and the 30-year risk of fatal myocardial infarction. New England Journal of Medicine 336, 1046-1053.

de Luis Roman DA, Bachiller P, Izaola O, Romero E, Martin J, Arranz M, Eiros Bouza JM \& Aller R (2001) Nutritional treatment for acquired immunodeficiency virus infection using an enterotropic peptide-based formula enriched with n-3 fatty acids: a randomized prospective trial. European Journal of Clinical Nutrition 55, 1048-1052.

Dooper MM, Wassink L, M'Rabet L \& Graus YM (2002) The modulatory effects of prostaglandin-E on cytokine production by human peripheral blood mononuclear cells are independent of the prostaglandin subtype. Immunology 107, 152-159.

Endres S, Ghorbani R, Kelley VE, Georgilis K, Lonnemann G, van der Meer JW et al. (1989) The effect of dietary supplementation with n-3 polyunsaturated fatty acids on the synthesis of interleukin-1 and tumor necrosis factor by mononuclear cells. New England Journal of Medicine 320, 265-271.

Endres S, Meydani SN, Ghorbani R, Schindler R \& Dinarello CA (1993) Dietary supplementation with n-3 fatty acids suppresses interleukin-2 production and mononuclear cell proliferation. Journal of Leukocyte Biology 54, 599-603.

Espersen GT, Grunnet N, Lervang HH, Nielsen GL, Thomsen BS, Faarvang KL, Dyerberg J \& Ernst E (1992) Decreased interleukin-1 beta levels in plasma from rheumatoid arthritis patients after dietary supplementation with n-3 polyunsaturated fatty acids. Clinical Rheumatology 11, 393-395.

Fearon KC, Barber MD, Moses AG, Ahmedzai SH, Taylor GS, Tisdale MJ \& Murray GD (2006) Double-blind, placebocontrolled, randomized study of eicosapentaenoic acid diester in patients with cancer cachexia. Journal of Clinical Oncology 24, 3401-3407.

Feldmann M \& Maini RN (1999) The role of cytokines in the pathogenesis of rheumatoid arthritis. Rheumatology 38, Suppl. 2, 3-7.

Furukawa K, Tashiro T, Yamamori H, Takagi K, Morishima Y, Sugiura T et al. (1999) Effects of soybean oil emulsion and eicosapentaenoic acid on stress response and immune function after a severely stressful operation. Annals of Surgery 229, $255-261$.

Gallai V, Sarchielli P, Trequattrini A, Franceschini M, Floridi A, Firenze C, Alberti A, Di Benedetto D \& Stragliotto E (1995) Cytokine secretion and eicosanoid production in the peripheral blood mononuclear cells of MS patients undergoing dietary supplementation with n-3 polyunsaturated fatty acids. Journal of Neuroimmunology 56, 143-153.

Gibney MJ \& Hunter B (1993) The effects of short- and longterm supplementation with fish oil on the incorporation of $n-3$ polyunsaturated fatty acids into cells of the immune system in healthy volunteers. European Journal of Clinical Nutrition 47, 255-259.

Gogos CA, Ginopoulos P, Salsa B, Apostolidou E, Zoumbos NC \& Kalfarentzos F (1998) Dietary omega-3 polyunsaturated fatty acids plus vitamin $\mathrm{E}$ restore immunodeficiency and prolong survival for severely ill patients with generalized malignancy: a randomized control trial. Cancer 82, 395-402.

Goldman DW, Pickett WC \& Goetzl EJ (1983) Human neutrophil chemotactic and degranulating activities of leukotriene B5 (LTB5) derived from eicosapentaenoic acid. Biochemical and Biophysical Research Communications 117, 282-288.

Gopaul NK, Anggard EE, Mallet AI, Betteridge DJ, Wolff SP \& Nourooz-Zadeh J (1995) Plasma 8-epi-PGF2 alpha levels are elevated in individuals with non-insulin dependent diabetes mellitus. FEBS Letters 368, 225-229.

Grimble RF, Howell WM, O'Reilly G, Turner SJ, Markovic O, Hirrell S, East JM \& Calder PC (2002) The ability of fish oil to suppress tumor necrosis factor alpha production by peripheral blood mononuclear cells in healthy men is associated with polymorphisms in genes that influence tumor necrosis factor alpha production. American Journal of Clinical Nutrition 76, 454-459.

Hallgren CG, Hallmans G, Jansson JH, Marklund SL, Huhtasaari F, Schutz A, Stromberg U, Vessby B \& Skerfving S (2001) Markers of high fish intake are associated with decreased risk of a first myocardial infarction. British Journal of Nutrition $\mathbf{8 6}$, 397-404.

Hawkes JS, Bryan DL, Makrides M, Neumann MA \& Gibson RA (2002) A randomized trial of supplementation with docosahexaenoic acid-rich tuna oil and its effects on the human milk cytokines interleukin 1 beta, interleukin 6 , and tumor necrosis factor alpha. American Journal of Clinical Nutrition 75, 754-760.

Healy DA, Wallace FA, Miles EA, Calder PC \& Newsholm P (2000) Effect of low-to-moderate amounts of dietary fish oil on neutrophil lipid composition and function. Lipids 35, 763-768.

Hellerstein MK, Wu K, McGrath M, Faix D, George D, Shackleton CH, Horn W, Hoh R \& Neese RA (1996) Effects of dietary n-3 fatty acid supplementation in men with weight loss associated with the acquired immune deficiency syndrome: Relation to indices of cytokine production. Journal of Acquired Immune Deficiency Syndromes and Human Retrovirology 11, $258-270$

Heyland DK, Novak F, Drover JW, Jain M, Su X \& Suchner U (2001) Should immunonutrition become routine in critically ill patients? A systematic review of the evidence. Journal of the American Medical Association 286, 944-953.

Hibbeln JR (1998) Fish consumption and major depression. Lancet 351, 1213.

Hibbeln JR (2002) Seafood consumption, the DHA content of mothers' milk and prevalence rates of postpartum depression: a cross-national, ecological analysis. Journal of Affective Disorders 69, 15-29.

Hommes DW \& van Deventer SJ (2000) Anti- and proinflammatory cytokines in the pathogenesis of tissue damage in 
Crohn's disease. Current Opinion in Clinical Nutrition and Metabolic Care 3, 191-195.

Hong S, Gronert K, Devchand PR, Moussignac RL \& Serhan CN (2003) Novel docosatrienes and 17S-resolvins generated from docosahexaenoic acid in murine brain, human blood, and glial cells. Autacoids in anti-inflammation. Journal of Biological Chemistry 278, 14677-14687.

Jellema A, Plat J \& Mensink RP (2004) Weight reduction, but not a moderate intake of fish oil, lowers concentrations of inflammatory markers and PAI-1 antigen in obese men during the fasting and postprandial state. European Journal of Clinical Investigation 34, 766-773.

Keithley JK, Swanson B, Zeller JM, Sha BE, Cohen M, Hershow R \& Novak R (2002) Comparison of standard and immuneenhancing oral formulas in asymptomatic HIV-infected persons: a multicenter randomized controlled clinical trial. Journal of Parenteral and Enteral Nutrition 26, 6-14.

Kelley DS, Taylor PC, Nelson GJ \& Mackey BE (1998a) Arachidonic acid supplementation enhances synthesis of eicosanoids without suppressing immune functions in young healthy men. Lipids 33, 125-130.

Kelley DS, Taylor PC, Nelson GJ \& Mackey BE (1998b) Dietary docosahexaenoic acid and immunocompetence in young healthy men. Lipids 33, 559-566.

Kelley DS, Taylor PC, Nelson GJ, Schmidt PC, Ferretti A, Erickson KL, Yu R, Chandra RK \& Mackey BE (1999) Docosahexaenoic acid ingestion inhibits natural killer cell activity and production of inflammatory mediators in young healthy men. Lipids 34, 317-324.

Kelley DS, Taylor PC, Nelson GJ, Schmidt PC, Mackey BE \& Kyle D (1997) Effects of dietary arachidonic acid on human immune response. Lipids 32, 449-456.

Kew S, Banerjee T, Minihane AM, Finnegan YE, Muggli R, Albers R, Williams CM \& Calder PC (2003) Lack of effect of foods enriched with plant- or marine-derived n-3 fatty acids on human immune function. American Journal of Clinical Nutrition 77, 1287-1295.

Kew S, Mesa MD, Tricon S, Buckley R, Minihane AM \& Yaqoob P (2004) Effects of oils rich in eicosapentaenoic and docosahexaenoic acids on immune cell composition and function in healthy humans. American Journal of Clinical Nutrition 79, 674-681.

Kramer TR, Schoene N, Douglass LW, Judd JT, Ballard-Barbash R, Taylor PR, Bhagavan HN \& Nair PP (1991) Increased vitamin $\mathrm{E}$ intake restores fish-oil-induced suppressed blastogenesis of mitogen-stimulated $\mathrm{T}$ lymphocytes. American Journal of Clinical Nutrition 54, 896-902.

Kremer JM, Lawrence DA, Jubiz W, DiGiacomo R, Rynes R, Bartholomew LE \& Sherman M (1990) Dietary fish oil and olive oil supplementation in patients with rheumatoid arthritis. Clinical and immunologic effects. Arthritis and Rheumatism 33, 810-820.

Kremer JM, Lawrence DA, Petrillo GF, Litts LL, Mullaly PM, Rynes RI et al. (1995) Effects of high-dose fish oil on rheumatoid arthritis after stopping nonsteroidal antiinflammatory drugs. Clinical and immune correlates. Arthritis and Rheumatism 38, 1107-1114.

Kronborg D, Hansen B \& Aaby P (1992) Analysis of the incubation period for measles in the epidemic in Greenland in 1951 using a variance components model. Statistics in Medicine 11, 579-590.

Lee TH, Hoover RL, Williams JD, Sperling RI, Ravalese J 3rd, Spur BW, Robinson DR, Corey EJ, Lewis RA \& Austen KF (1985) Effect of dietary enrichment with eicosapentaenoic and docosahexaenoic acids on in vitro neutrophil and monocyte leukotriene generation and neutrophil function. New England Journal of Medicine 312, 1217-1224.
Lee TH, Menica-Huerta JM, Shih C, Corey EJ, Lewis RA \& Austen KF (1984) Characterization and biologic properties of 5,12-dihydroxy derivatives of eicosapentaenoic acid, including leukotriene B5 and the double lipoxygenase product. Journal of Biological Chemistry 259, 2383-2389.

Lewis RA, Austen KF \& Soberman RJ (1990) Leukotrienes and other products of the 5-lipoxygenase pathway. Biochemistry and relation to pathobiology in human diseases. New England Journal of Medicine 323, 645-655.

Lima AA, Silva TM, Gifoni AM, Barrett LJ, McAuliffe IT, Bao Y, Fox JW, Fedorko DP \& Guerrant RL (1997) Mucosal injury and disruption of intestinal barrier function in HIV-infected individuals with and without diarrhea and cryptosporidiosis in northeast Brazil. American Journal of Gastroenterology 92, 1861-1866.

McGowan I, Elliott J, Fuerst M, Taing P, Boscardin J, Poles M \& Anton P (2004) Increased HIV-1 mucosal replication is associated with generalized mucosal cytokine activation. Journal of Acquired Immune Deficiency Syndromes 37, 1228-1236.

McGowan I, Radford-Smith G \& Jewell DP (1994) Cytokine gene expression in HIV-infected intestinal mucosa. AIDS 8, $1569-1575$.

McKay DM \& Baird AW (1999) Cytokine regulation of epithelial permeability and ion transport. Gut 44, 283-289.

Mandrup-Poulsen T, Helqvist S, Molvig J, Wogensen LD \& Nerup J (1989) Cytokines as immune effector molecules in autoimmune endocrine diseases with special reference to insulin-dependent diabetes mellitus. Autoimmunity 4, 191218.

Marcheselli VL, Hong S, Lukiw WJ, Tian XH, Gronert K, Musto A, Hardy M, Gimenez JM, Chiang N, Serhan CN \& Bazan NG (2003) Novel docosanoids inhibit brain ischemia-reperfusionmediated leukocyte infiltration and pro-inflammatory gene expression. Journal of Biological Chemistry 278, 4380743817.

Matsuyama W, Mitsuyama H, Watanabe M, Oonakahara K, Higashimoto I, Osame M \& Arimura K (2005) Effects of omega-3 polyunsaturated fatty acids on inflammatory markers in COPD. Chest 128, 3817-3827.

Merchant AT, Curhan GC, Rimm EB, Willett WC \& Fawzi WW (2005) Intake of n-6 and n-3 fatty acids and fish and risk of community-acquired pneumonia in US men. American Journal of Clinical Nutrition 82, 668-674.

Meydani SN, Endres S, Woods MM, Goldin BR, Soo C, MorrillLabrode A, Dinarello CA \& Gorbach SL (1991) Oral (n-3) fatty acid supplementation suppresses cytokine production and lymphocyte proliferation: comparison between young and older women. Journal of Nutrition 121, 547-555.

Meydani SN, Lichtenstein AH, Cornwall S, Meydani M, Goldin BR, Rasmussen H, Dinarello CA \& Schaefer EJ (1993) Immunologic effects of national cholesterol education panel step-2 diets with and without fish-derived N-3 fatty acid enrichment. Journal of Clinical Investigation 92, 105-113.

Mickleborough TD, Lindley MR, Ionescu AA \& Fly AD (2006) Protective effect of fish oil supplementation on exerciseinduced bronchoconstriction in asthma. Chest 129, 39-49.

Miles EA, Allen E \& Calder PC (2002) In vitro effects of eicosanoids derived from different 20 -carbon fatty acids on production of monocyte-derived cytokines in human whole blood cultures. Cytokine 20, 215-223.

Miles EA, Aston L \& Calder PC (2003) In vitro effects of eicosanoids derived from different 20-carbon fatty acids on $\mathrm{T}$ helper type 1 and $\mathrm{T}$ helper type 2 cytokine production in human whole-blood cultures. Clinical and Experimental Allergy 33, 624-632.

Miles EA, Banerjee T \& Calder PC (2004a) The influence of different combinations of gamma-linolenic, stearidonic and 
eicosapentaenoic acids on the fatty acid composition of blood lipids and mononuclear cells in human volunteers. Prostaglandins, Leukotrienes, and Essential Fatty Acids 70, 529538.

Miles EA, Banerjee T, Dooper MM, M'Rabet L, Graus YM \& Calder PC (2004b) The influence of different combinations of gamma-linolenic acid, stearidonic acid and EPA on immune function in healthy young male subjects. British Journal of Nutrition 91, 893-903.

Miles EA, Banerjee T, Wells SJ \& Calder PC (2006) Limited effect of eicosapentaenoic acid on T-lymphocyte and natural killer cell numbers and functions in healthy young males. Nutrition 22, 512-519.

Molvig J, Pociot F, Worsaae H, Wogensen LD, Baek L, Christensen $\mathrm{P}$ et al. (1991) Dietary supplementation with omega-3polyunsaturated fatty acids decreases mononuclear cell proliferation and interleukin-1 beta content but not monokine secretion in healthy and insulin-dependent diabetic individuals. Scandinavian Journal of Immunology 34, 399-410.

Mori TA, Woodman RJ, Burke V, Puddey IB, Croft KD \& Beilin LJ (2003) Effect of eicosapentaenoic acid and docosahexaenoic acid on oxidative stress and inflammatory markers in treatedhypertensive type 2 diabetic subjects. Free Radical Biology and Medicine 35, 772-781.

Morley JE, Thomas DR \& Wilson MM (2006) Cachexia: pathophysiology and clinical relevance. American Journal of Clinical Nutrition 83, 735-743.

Morris MC, Evans DA, Bienias JL, Tangney CC, Bennett DA, Wilson RS, Aggarwal N \& Schneider J (2003) Consumption of fish and n-3 fatty acids and risk of incident Alzheimer disease. Archives of Neurology 60, 940-946.

Mosmann TR \& Sad S (1996) The expanding universe of T-cell subsets: Th1, Th2 and more. Immunology Today 17, 138-146.

Mukherjee PK, Marcheselli VL, Serhan CN \& Bazan NG (2004) Neuroprotectin D1: a docosahexaenoic acid-derived docosatriene protects human retinal pigment epithelial cells from oxidative stress. Proceedings of the National Academy of Sciences USA 101, 8491-8496.

Murray CJ \& Lopez AD (1997) Alternative projections of mortality and disability by cause 1990-2020: global Burden of Disease Study. Lancet 349, 1498-1504.

Nilsson J, Jovinge S, Niemann A, Reneland R \& Lithell H (1998) Relation between plasma tumor necrosis factor-alpha and insulin sensitivity in elderly men with non-insulin-dependent diabetes mellitus. Arteriosclerosis, Thrombosis, and Vascular Biology 18, 1199-1202.

Nusrat A, Turner JR \& Madara JL (2000) Molecular physiology and pathophysiology of tight junctions. IV. Regulation of tight junctions by extracellular stimuli: nutrients, cytokines, and immune cells. American Journal of Physiology 279, G851-G857.

Oomen CM, Feskens EJ, Rasanen L, Fidanza F, Nissinen AM, Menotti A, Kok FJ \& Kromhout D (2000) Fish consumption and coronary heart disease mortality in Finland, Italy, and The Netherlands. American Journal of Epidemiology 151, 999-1006.

Persson C, Glimelius B, Ronnelid J \& Nygren P (2005) Impact of fish oil and melatonin on cachexia in patients with advanced gastrointestinal cancer: a randomized pilot study. Nutrition 21, $170-178$.

Peterson LD, Jeffery NM, Thies F, Sanderson P, Newsholme EA \& Calder PC (1998) Eicosapentaenoic and docosahexaenoic acids alter rat spleen leukocyte fatty acid composition and prostaglandin E2 production but have different effects on lymphocyte functions and cell-mediated immunity. Lipids 33, 171-180.
Pichard C, Sudre P, Karsegard V, Yerly S, Slosman DO, Delley V, Perrin L \& Hirschel B (1998) A randomized double-blind controlled study of 6 months of oral nutritional supplementation with arginine and omega-3 fatty acids in HIV-infected patients. Swiss HIV Cohort Study. AIDS 12, 53-63.

Pradhan AD, Manson JE, Rifai N, Buring JE \& Ridker PM (2001) C-reactive protein, interleukin 6, and risk of developing type 2 diabetes mellitus. Journal of the American Medical Association 286, 327-334.

Rees D, Miles EA, Banerjee T, Wells SJ, Roynette CE, Wahle KW \& Calder PC (2006) Dose-related effects of eicosapentaenoic acid on innate immune function in healthy humans: a comparison of young and older men. American Journal of Clinical Nutrition 83, 331-342.

Reka S, Garro ML \& Kotler DP (1994) Variation in the expression of human immunodeficiency virus RNA and cytokine mRNA in rectal mucosa during the progression of infection. Lymphokine and Cytokine Research 13, 391-398.

Sano H, Hla T, Maier JA, Crofford LJ, Case JP, Maciag T \& Wilder RL (1992) In vivo cyclooxygenase expression in synovial tissues of patients with rheumatoid arthritis and osteoarthritis and rats with adjuvant and streptococcal cell wall arthritis. Journal of Clinical Investigation 89, 97-108.

Schmidt EB, Varming K, Moller JM, Bulow Pedersen I, Madsen P \& Dyerberg J (1996) No effect of a very low dose of n-3 fatty acids on monocyte function in healthy humans. Scandinavian Journal of Clinical and Laboratory Investigation 56, 87-92.

Schmitz H, Rokos K, Florian P, Gitter AH, Fromm M, Scholz P, Ullrich R, Zeitz M, Pauli G \& Schulzke JD (2002) Supernatants of HIV-infected immune cells affect the barrier function of human HT-29/B6 intestinal epithelial cells. AIDS 16, 983-991.

Serhan CN (2005) Novel eicosanoid and docosanoid mediators: resolvins, docosatrienes, and neuroprotectins. Current Opinion in Clinical Nutrition and Metabolic Care 8, 115-121.

Serhan CN, Arita M, Hong S \& Gotlinger K (2004) Resolvins, docosatrienes, and neuroprotectins, novel omega-3-derived mediators, and their endogenous aspirin-triggered epimers. Lipids 39, 1125-1132.

Sharon P \& Stenson WF (1984) Enhanced synthesis of leukotriene B4 by colonic mucosa in inflammatory bowel disease. Gastroenterology 86, 453-460.

Sharpstone DR, Rowbottom AW, Nelson MR, Lepper MW \& Gazzard BG (1996) Faecal tumour necrosis factor-alpha in individuals with HIV-related diarrhoea. AIDS 10, 989-994.

Simopoulos AP (1998) Overview of evolutionary aspects of omega 3 fatty acids in the diet. World Review of Nutrition and Dietetics 83, 1-11.

Soyland E, Lea T, Sandstad B \& Drevon A (1994) Dietary supplementation with very long-chain $\mathrm{n}-3$ fatty acids in man decreases expression of the interleukin-2 receptor (CD25) on mitogen-stimulated lymphocytes from patients with inflammatory skin diseases. European Journal of Clinical Investigation 24, 236-242.

Sperling RI (1995) Eicosanoids in rheumatoid arthritis. Rheumatic Diseases Clinics of North America 21, 741-758.

Sperling RI, Benincaso AI, Knoell CT, Larkin JK, Austen KF \& Robinson DR (1993) Dietary omega-3 polyunsaturated fatty acids inhibit phosphoinositide formation and chemotaxis in neutrophils. Journal of Clinical Investigation 91, 651-660.

Stockmann M, Schmitz H, Fromm M, Schmidt W, Pauli G, Scholz P, Riecken EO \& Schulzke JD (2000) Mechanisms of epithelial barrier impairment in HIV infection. Annals of the New York Academy of Sciences 915, 293-303.

Stockmann M, Schmitz H, Fromm M, Schmidt W, Rokos K, Pauli G, Scholz P, Riecken EO \& Schulzke JD (1998) The 
mechanism of diarrhea in HIV is based on an impaired epithelial barrier function that could be induced by a specific cytokine pattern. Annals of the New York Academy of Sciences 859, 267-270.

Sundrarjun T, Komindr S, Archararit N, Dahlan W, Puchaiwatananon O, Angthararak S, Udomsuppayakul U \& Chuncharunee S (2004) Effects of n-3 fatty acids on serum interleukin-6, tumour necrosis factor-alpha and soluble tumour necrosis factor receptor p55 in active rheumatoid arthritis. Journal of International Medical Research 32, 443-454.

Takagi K, Yamamori H, Furukawa K, Miyazaki M \& Tashiro T (2001) Perioperative supplementation of EPA reduces immunosuppression induced by postoperative chemoradiation therapy in patients with esophageal cancer. Nutrition 17, 478-479.

Tashiro T, Yamamori H, Takagi K, Hayashi N, Furukawa K \& Nakajima N (1998) n-3 versus n-6 polyunsaturated fatty acids in critical illness. Nutrition 14, 551-553.

Thies F, Miles EA, Nebe-von-Caron G, Powell JR, Hurst TL, Newsholme EA \& Calder PC (2001a) Influence of dietary supplementation with long-chain $n-3$ or $n-6$ polyunsaturated fatty acids on blood inflammatory cell populations and functions and on plasma soluble adhesion molecules in healthy adults. Lipids 36, 1183-1193.

Thies F, Nebe-von-Caron G, Powell JR, Yaqoob P, Newsholme EA \& Calder PC (2001b) Dietary supplementation with eicosapentaenoic acid, but not with other long-chain n-3 or n-6 polyunsaturated fatty acids, decreases natural killer cell activity in healthy subjects aged $>55 \mathrm{y}$. American Journal of Clinical Nutrition 73, 539-548.

Thies F, Nebe-von-Caron G, Powell JR, Yaqoob P, Newsholme EA \& Calder PC (2001c) Dietary supplementation with gamma-linolenic acid or fish oil decreases T lymphocyte proliferation in healthy older humans. Journal of Nutrition 131, 1918-1927.

Tilley SL, Coffman TM \& Koller BH (2001) Mixed messages: modulation of inflammation and immune responses by prostaglandins and thromboxanes. Journal of Clinical Investigation 108, 15-23.

Todorov P, Cariuk P, McDevitt T, Coles B, Fearon K \& Tisdale M (1996) Characterization of a cancer cachectic factor. Nature 379, 739-742.

Trebble T, Arden NK, Stroud MA, Wootton SA, Burdge GC, Miles EA, Ballinger AB, Thompson RL \& Calder PC (2003a) Inhibition of tumour necrosis factor-alpha and interleukin 6 production by mononuclear cells following dietary fish-oil supplementation in healthy men and response to antioxidant co-supplementation. British Journal of Nutrition 90, 405-412.

Trebble TM, Arden NK, Wootton SA, Calder PC, Mullee MA, Fine DR \& Stroud MA (2004) Fish oil and antioxidants alter the composition and function of circulating mononuclear cells in Crohn disease. American Journal of Clinical Nutrition 80, 1137-1144.

Trebble TM, Wootton SA, Miles EA, Mullee M, Arden NK, Ballinger AB, Stroud MA, Burdge GC \& Calder PC (2003b) Prostaglandin E2 production and $\mathrm{T}$ cell function after fish-oil supplementation: response to antioxidant cosupplementation. American Journal of Clinical Nutrition 78, 376-382.

Vega-Lopez S, Kaul N, Devaraj S, Cai RY, German B \& Jialal I (2004) Supplementation with omega3 polyunsaturated fatty acids and all-rac alpha-tocopherol alone and in combination failed to exert an anti-inflammatory effect in human volunteers. Metabolism: Clinical and Experimental 53, 236-240.

Virella G, Fourspring K, Hyman B, Haskill-Stroud R, Long L, Virella I, La Via M, Gross AJ \& Lopes-Virella M (1991) Immunosuppressive effects of fish oil in normal human volunteers: correlation with the in vitro effects of eicosapentanoic acid on human lymphocytes. Clinical Immunology and Immunopathology 61, 161-176.

Virgili N, Farriol M, Castellanos JM, Giro M, Podzamczer D \& Pita AM (1997) Evaluation of immune markers in asymptomatic AIDS patients receiving fish oil supplementation. Clinical Nutrition 16, 257-261.

Wallace FA, Miles EA \& Calder PC (2003) Comparison of the effects of linseed oil and different doses of fish oil on mononuclear cell function in healthy human subjects. British Journal of Nutrition 89, 679-689.

Wigmore SJ, Fearon KC, Maingay JP \& Ross JA (1997) Down-regulation of the acute-phase response in patients with pancreatic cancer cachexia receiving oral eicosapentaenoic acid is mediated via suppression of interleukin-6. Clinical Science London 92, 215-221.

Wu D, Han SN, Meydani M \& Meydani SN (2004) Effect of concomitant consumption of fish oil and vitamin $\mathrm{E}$ on production of inflammatory cytokines in healthy elderly humans. Annals of the New York Academy of Sciences 1031, $422-424$.

Yaqoob P, Pala HS, Cortina-Borja M, Newsholme EA \& Calder PC (2000) Encapsulated fish oil enriched in alpha-tocopherol alters plasma phospholipid and mononuclear cell fatty acid compositions but not mononuclear cell functions. European Journal of Clinical Investigation 30, 260-274. 